\title{
Reducing voltage-dependent potassium channel Kv3.4 levels ameliorates synapse loss in a mouse model of Alzheimer's disease
}

Jie Yeap, ${ }^{1}$ Chaitra Sathyaprakash, ${ }^{1}$ Jamie Toombs, ${ }^{1}$ Jane Tulloch, ${ }^{1}$ Cristina Scutariu, ${ }^{1}$ Jamie Rose,${ }^{1}$ Karen Burr, ${ }^{2}$ Caitlin Davies, ${ }^{1}$ Marti Colom-Cadena, ${ }^{1}$ Siddharthan Chandran, ${ }^{2}$ Charles H Large, ${ }^{3}$ Matthew JM Rowan, ${ }^{4}$ Martin J Gunthorpe, ${ }^{3}$ Tara L Spires-Jones ${ }^{1}$

1. UK Dementia Research Institute and Centre for Discovery Brain Sciences, University of Edinburgh, UK

2. UK Dementia Research Institute and Centre for Clinical Brain Sciences, University of Edinburgh UK

3. Autifony Therapeutics Limited, Stevenage Bioscience Catalyst, Stevenage, UK

4. Emory University School of Medicine, Atlanta, GA, USA

\section{Corresponding author:}

Tara L Spires-Jones

UK Dementia Research Institute and Centre for Discovery Brain Sciences,

University of Edinburgh

1 George Square

Edinburgh, EH8 9JZ UK

Tara.spires-jones@ed.ac.uk

\section{Abstract}

Synapse loss is associated with cognitive decline in Alzheimer's disease (AD) and owing to their plastic nature, synapses are an ideal target for therapeutic intervention. Oligomeric amyloid beta $(A \beta)$ around amyloid plaques is known to contribute to synapse loss in mouse models and is associated with synapse loss in human AD brain tissue, but the mechanisms leading from $A \beta$ to synapse loss remain unclear. Recent data suggest that the fast-activating and -inactivating voltagegated potassium channel subtype $3.4\left(\mathrm{~K}_{\mathrm{v}} 3.4\right)$ may play a role in $A \beta$-mediated neurotoxicity. Here, we tested whether this channel could also be involved in $A \beta$ synaptotoxicity. Using adeno-associated virus and CRISPR (clustered regularly interspaced short palindromic repeats) technology, we reduced $\mathrm{K}_{\mathrm{v}} 3.4$ expression in neurons of the somatosensory cortex of APP/PS1 mice. These mice express human familial $A D$ associated mutations in amyloid precursor protein and presenilin 1 and develop amyloid plaques and plaque-associated synapse loss similar to that observed in AD brain. We observe that reducing $\mathrm{K}_{\mathrm{v}} 3.4$ levels ameliorates dendritic spine loss and changes spine morphology compared to control virus. In support of translational relevance, $\mathrm{K}_{\mathrm{v}} 3.4$ protein was observed in human AD and control brain and is associated with synapses in human iPSC-derived cortical neurons. Interestingly, we observe a decrease in $\mathrm{K}_{\mathrm{v}} 3.4$ expression in iPSC derived cortical neurons when they are challenged with human Alzheimer's disease derived brain homogenate. These results suggest that approaches to reduce $\mathrm{K}_{\mathrm{v}} 3.4$ expression and/or function could be protective against $A \beta$-induced synaptic alterations. 


\section{Introduction}

Alzheimer's disease (AD) is characterised by the progressive accumulation of amyloid plaques and neurofibrillary tangles, composed of abnormally aggregated $\beta$-amyloid (A $\beta$ ) and hyperphosphorylated tau proteins, respectively (Serrano-Pozo et al., 2011). Along with these neuropathological lesions there is extensive neuronal loss, synapse loss, and gliosis (Henstridge et al., 2019). Of these brain changes, synapse loss is the strongest correlate of cognitive decline in $A D$ (DeKosky \& Scheff, 1990; Terry et al, 1991), and synapses, with their myriad receptors and ion channels, are attractive therapeutic targets for intervention (Colom-Cadena et al., 2020). In brains affected by $A D$ and in mouse models of amyloid plaque formation, plaques act as a local reservoir of oligomeric $A \beta$, emanating these soluble and diffusible $A \beta$ species to form a halo surrounding plaques which is associated with synapse loss (Koffie et al., 2009, 2012; Spires-Jones \& Hyman, 2014). While the synaptotoxicity of oligomeric $A \beta$ is well-established, it is not yet entirely clear how synapses are damaged or whether this can be recovered by therapeutic interventions.

One potential pathway mediating $A \beta$ synaptotoxicity involves voltage-gated potassium channels. The voltage-gated potassium channel subtype $3.4\left(\mathrm{~K}_{\mathrm{v}} 3.4\right)$ encoded by the KCNC4 gene is a member of the $\mathrm{K}_{\mathrm{v}} 3$ family of channels that play important roles in controlling neuronal firing and contribute to synaptic plasticity (Kaczmarek \& Zhang, 2017; Rowan \& Christie, 2017). This channel is believed to have vital roles in regulating neurotransmitter release and mediating neuronal excitability and plasticity given its pre- and postsynaptic localisation (Kaczmarek \& Zhang, 2017; Rowan et al., 2016). Dysregulation of $K_{v} 3.4$ channel expression has been implicated in several neurological conditions due to it's role in pathways linked to oxidative stress and hypoxia (Kääb et al., 2005; Song et al., 2017). $\mathrm{K}_{\mathrm{v}} 3$ channels are also involved in signalling pathways linked to neurodegenerative diseases such as spinal cerebellar ataxia (Zhang \& Kaczmarek, 2016). In early and late stages of $A D, K_{v} 3.4$ gene expression was increased in a study of frontal cortex from 7 donors $(2$ control, 3 early $A D$ and 2 late AD cases) (Angulo et al., 2004). In this same study, protein level measured by western blot was also increased in AD compared to control frontal cortex, and Kv3.4 staining with immunohistochemistry was observed in a punctate pattern in all cases, with some accumulation around plaques in AD samples (Angulo et al., 2004). Further, increased $K_{v} 3.4$ protein levels were observed in 3 Tg2576 transgenic mice (which develop amyloid plaques) compared to 3 wild-type mice (Angulo et al., 2004). A subsequent study in the same mouse line specifically demonstrated astrocytic upregulation of $\mathrm{K}_{\mathrm{v}} 3.4$ and that lowering $\mathrm{K}_{\mathrm{v}} 3.4$ levels caused downregulation of a reactive astrocyte marker and $A \beta$ oligomers (Boscia et al., 2017). This observation may be linked with the notion that the $\mathrm{K}_{\mathrm{v}} 3.4$-mediated $\mathrm{K}^{+}$efflux is implicated in the activation of astrocytic inflammasomes and reduced astrocytic phagocytosis in the early stages of AD (Boscia et al, 2017; 
Piccialli et al, 2020). High concentrations of $A \beta(5 \mu \mathrm{M})$ applied to rat primary hippocampal neuronal cultures or differentiated PC12 cells also induced $\mathrm{K}_{\mathrm{v}} 3.4$ expression and morphological abnormalities which could be prevented by inhibiting $\mathrm{K}_{\mathrm{v}} 3.4$ channel activity (Ciccone et al., 2019; Pannaccione et al., 2007).

Here we tested the hypothesis that $K_{v} 3.4$ channels play an important role in pathways that mediate toxicity towards synapses in the Alzheimer's brain and that reducing levels of this channel can protect synapses from $A \beta$-induced degeneration. To test this hypothesis, we examined dendritic spines in plaque-bearing APP/PS1 mice and littermate controls with and without lowering $K_{v} 3.4$ expression. Further we examine human iPSC-derived cortical neurons and human post-mortem brain tissue to determine whether $K_{v} 3.4$ is indeed expressed in synapses where it may mediate $A \beta$ toxicity.

\section{Materials and Methods}

\section{Mice}

APPswe/PS1dE9 (APP/PS1, $n=10$ ) mice originally purchased from Jackson Laboratory were bred and aged in house. These double transgenic mice overexpress a human mutant amyloid precursor protein gene with the Swedish mutation and a human mutant Presenilin 1 gene with the deletion of exon 9 (Jankowsky et al, 2004). Wild-type (WT, $n=6$ ) littermates were used as controls. Both sexes of mice were used. All mice were group housed in a 12-hour day/night cycle with ad libitum access to food and water. All mice underwent surgery for stereotaxic injections at 7 months of age and were sacrificed 7 weeks post-injection for brain collections. Table 1 shows a summary of the mice used in this study. Experiments were performed in accordance with the UK Animal (Scientific Procedures) Act 1986 and the Directive 2010/63EU of the European Parliament and the Council on the protection of animals used for scientific purposes.

\section{Viral Vectors}

Adeno-associated viruses (AAVs) were used encoding the red fluorescent protein tdTomato, enhanced yellow fluorescent protein (eYFP) or the single guide RNA (sgRNA) that cleaves K 3.4/KCNC4: pENN.AAV.CAG.tdTomato.WPRE.SV40 \#105554), pAAV.CamKII(1.3).eYFP.WPRE.hGH (Addgene \#10522), U6.sgRNA(mKv3.4).CMV.saCas9, respectively. Prior to use, $2 \mu \mathrm{L}$ of pENN.AAV.CAG.tdTomato.WPRE.SV40 $\left(1 \times 10^{13} \mathrm{GC} / \mathrm{mL}\right)$ was diluted with an equal volume of $0.1 \mathrm{M}$ phosphate buffer saline (PBS) while $2 \mu \mathrm{L}$ of pAAV.CamKII(1.3).eYFP.WPRE.hGH $\left(1 \times 10^{13} \mathrm{GC} / \mathrm{mL}\right)$ was mixed with $2 \mu \mathrm{L}$ of U6.sgRNA(mK $\left.\mathrm{m}_{\mathrm{v}} 3.4\right)$. CMV.saCas9 $\left(1 \times 10^{11} \mathrm{GC} / \mathrm{mL}\right)$. 


\section{Stereotaxic surgery}

At 7 months of age, mice were anaesthetised with isofluorane (3\% for induction, $0.5-2 \%$ for maintenance). Fur on the head of the mice was shaved and Viscotears liquid gel was applied over both eyes before the animals were secured using ear bars in a stereotaxic apparatus. Body temperature was regulated using a heating pad and a rectal probe thermometer. After sterilising the surgical site with betadine and isopropyl alcohol, and performing local anaesthesia with subcutaneous injection of xylocaine ( $2 \mu \mathrm{g} / \mathrm{g}$ body weight), a 2-3 mm incision was made in the scalp to expose the skull. Burr holes were drilled in the skull, $1.5 \mathrm{~mm}$ bilaterally and $1 \mathrm{~mm}$ posterior to Bregma. Using a $10 \mu \mathrm{L}$ Hamilton syringe, $4 \mu \mathrm{L}$ of viral preparation was injected $0.7 \mathrm{~mm}$ deep into each burr hole on both somatosensory cortices at a rate of $420 \mathrm{~nL} / \mathrm{sec}$. Each hemisphere was randomly assigned to either experimental ( $\left.\mathrm{K}_{\mathrm{v}} 3.4-\mathrm{knockdown}\right)$ or control condition and received corresponding AAV viral injections into the somatosensory cortex ( $K_{\mathrm{v}} 3.4-k$ nockdown hemisphere: pAAV.CamKII(1.3).eYFP.WPRE.hGH : U6.sgRNA(mK $\left.{ }_{v} 3.4\right) . C M V . s a C a s 9, ~ 1: 1 ;$ Control hemisphere: pENN.AAV.CAG.tdTomato.WPRE.SV40 : PBS, 1:1). After injections, the scalp was sutured and mice were allowed to recover from anaesthesia in a heated chamber. Injected mice were singly housed under standard conditions until brains were harvested.

\section{Mouse brain tissue processing}

After a 7-week incubation period to allow viral expression in neurons, the mice were euthanised and perfused transcardially with PBS followed by $4 \%$ paraformaldehyde (PFA; Agar Scientific, AGR1026). The brains extracted from the skull and post-fixed at $4^{\circ} \mathrm{C}$ for two hours before they were sectioned on a vibratome. Coronal sections of $50 \mu \mathrm{m}$ thickness were collected between Bregma 0 and -2 to include the injection sites within the somatosensory cortices. Brain slices with eYFP (visualisation of $\mathrm{K}_{\mathrm{v}}$ 3.4-knockdown condition) and tdTomato (control condition) expression were isolated after a quick examination under an epifluorescence microscope. These eYFP- and tdTomato-positive slices were then post-fixed in $4 \%$ PFA for another 20 minutes and stored in PBS at $4^{\circ} \mathrm{C}$ until use.

\section{Immunohistochemistry and Microscopy}

For measurement of $K_{v} 3.4$ expression within injection sites, $50 \mu \mathrm{m}$ floating slices were stained with an antibody specific to $K_{v} 3.4$ (Alomone Labs, APC-019) and an anti-rabbit Alexa Fluor Plus 647conjugated secondary antibody (Invitrogen, A32795). After blocking the brain slices in $0.5 \%$ Triton- $X$ 100 in PBS containing 3\% normal donkey serum for an hour, samples were incubated with the primary antibody solution (1:200 dilution in blocking buffer) at $4^{\circ} \mathrm{C}$ overnight. The slices were washed in PBS and left in secondary antibody solution (1:5,000 dilution in blocking buffer) for two hours. To stain plaques, brain slices were mounted on microscope slides which were then dipped in $0.05 \%$ Thioflavin $S$ in $50 \%$ ethanol for 8 minutes, followed by differentiation with $80 \%$ ethanol for 15 
seconds. Immu-mount (Thermo Scientific \#9990402) was applied before the samples were covered with a glass coverslip.

\section{Confocal imaging and analysis of mouse brains}

To confirm $\mathrm{K}_{\mathrm{v}} 3.4$ reduction in the experimental versus control hemisphere, images stacks $(61.5 \mu \mathrm{m} x$ $61.5 \mu \mathrm{m} \times 10-28 \mu \mathrm{m}$ with a z-step $0.3 \mu \mathrm{m}, 63 \times$ zoom 3, N.A. 1.4) of tdTomato- and eYFP-positive cell bodies ( $n=\sim 10$ images per mouse) were acquired on a Leica TCS SP8 confocal microscope using laser excitation at $488 \mathrm{~nm}$ for eYFP, $552 \mathrm{~nm}$ for tdTomato and $638 \mathrm{~nm}$ for $\mathrm{K}_{\mathrm{v}} 3.4$ staining with Alexa Fluor Plus 647 conjugated secondary. Using ImageJ (Schneider et al., 2012), the mean intensity of $K_{\mathrm{v}} 3.4$ staining of cell bodies was measured. The $K_{v} 3.4$ staining intensities of cell bodies were normalised to background intensity measured in the same stack and z-section. Table 1 summarises the number of cell bodies analysed and the mean staining intensity of each animal.

To examine the effect of $K_{v} 3.4-k n o c k d o w n$ on dendritic spine densities, image stacks (61.5 $\mu \mathrm{m} \times 61.5 \mu \mathrm{m} \times 3-25 \mu \mathrm{m}$ with a z-step $0.3 \mu \mathrm{m}, 63 \times$ zoom 3, N.A. 1.4) of dendritic segments, either labelled with eYFP or tdTomato, from cortical layer II, III and V pyramidal neurons were acquired. Only dendritic segments more than $20 \mu \mathrm{m}$ in length were selected. For every APP/PS1 mouse, dendritic segments were captured for each condition: eYFP-positive, near a plaque (0-30 $\mu \mathrm{m}$, using laser excitation $405 \mathrm{~nm}$ for ThioS staining); eYFP-positive, far from plaques ( $>30 \mu \mathrm{m}$ ); tdTomatopositive, near a plaque and tdTomato-positive, far from plaques. As WT mice do not present plaques, dendrite selection was made without regard to plaque proximity. Prior to image analysis, all images were randomly code-blinded by an observer and the quantification of spine densities was performed on greyscale images, thereby avoiding experimenter bias. Z-stack reconstructions and measurements were performed in ImageJ. The distance of dendrite segments to the nearest plaque, if present, was measured. The selected dendritic segments were traced in detail to count the number of spines present and their morphological class recorded, either as mushroom, thin, stubby or branched. Branched spines had more than one head (Harris et al, 1992; Peters \& KaisermanAbramof, 1970; Spires et al, 2005b). Mushroom spines had a clear protrusion with head diameter $\geq$ $2 \mathrm{x}$ neck diameter. Thin spines had similar head and neck diameter (head diameter $<2 \mathrm{x}$ neck diameter), while stubby spines had no visible neck (head diameter < neck diameter). The length of dendrite segments were measured to calculate linear spine density ( $n$ spine per $\mu \mathrm{m}$ along the dendrite). Dendritic shaft diameters were also measured at each end and the midpoint of each segment to produce an average diameter. The number of dendritic segments analysed and the mean spine density of each animal are shown in Table 1. 
Table 1. Summary of mice used in this study. Only a subset of APP/PS1 mice were analysed for $K_{v} 3.4$ staining intensity. N.A.: Not applicable.

\begin{tabular}{|c|c|c|c|c|c|c|c|c|}
\hline \multirow{3}{*}{$\begin{array}{c}\text { Mouse } \\
\text { ID }\end{array}$} & \multirow[t]{3}{*}{ Genotype } & \multirow[t]{3}{*}{ Sex } & \multicolumn{4}{|c|}{$\begin{array}{c}\text { Spine density } \\
\text { Mean ( } N \text { dendritic segments) }\end{array}$} & \multicolumn{2}{|c|}{$\begin{array}{c}\mathrm{K}_{\mathrm{v}} 3.4 \text { intensity } \\
\text { (normalised to } \\
\text { background) } \\
\text { Mean ( } N \text { cell bodies) }\end{array}$} \\
\hline & & & \multicolumn{2}{|c|}{ tdTomato (Control) } & \multicolumn{2}{|c|}{$\begin{array}{l}\text { eYFP (K } 3.4 \\
\text { knockdown) }\end{array}$} & \multirow{2}{*}{$\begin{array}{l}\text { tdTomato } \\
\text { (Control) }\end{array}$} & \multirow{2}{*}{$\begin{array}{l}\text { eYFP ( } K_{v} 3.4 \\
\text { knockdown) }\end{array}$} \\
\hline & & & Far & Near & Far & Near & & \\
\hline TS23 & WT & $F$ & $1.82(20)$ & N.A. & $2.38(20)$ & N.A. & $3.10(14)$ & $2.34(10)$ \\
\hline TS25 & WT & $\mathrm{F}$ & $2.11(20)$ & N.A. & $2.52(20)$ & N.A. & $2.65(10)$ & $2.32(10)$ \\
\hline TS511 & WT & $M$ & $1.59(20)$ & N.A. & $2.37(20)$ & N.A. & $2.79(13)$ & $2.34(16)$ \\
\hline TS517 & WT & $\mathrm{F}$ & $1.77(20)$ & N.A. & $2.42(20)$ & N.A. & $2.30(9)$ & $2.30(11)$ \\
\hline TS531 & WT & M & $2.07(20)$ & N.A. & $2.12(20)$ & N.A. & $2.46(10)$ & $2.00(14)$ \\
\hline TS532 & WT & M & $0.80(20)$ & N.A. & $1.17(20)$ & N.A. & $1.85(11)$ & $1.48(10)$ \\
\hline TS476 & APP/PS1 & $\mathrm{F}$ & $0.66(20)$ & $0.58(24)$ & $0.64(20)$ & $0.48(32)$ & - & - \\
\hline TS478 & APP/PS1 & $\mathrm{F}$ & $0.72(10)$ & $0.53(37)$ & $0.66(19)$ & $0.52(30)$ & - & - \\
\hline TS481 & APP/PS1 & $M$ & $0.80(12)$ & $0.61(26)$ & $1.33(23)$ & $0.79(24)$ & - & - \\
\hline TS499 & APP/PS1 & $F$ & $0.48(26)$ & $0.46(37)$ & $0.49(12)$ & $0.46(29)$ & - & - \\
\hline TS518 & APP/PS1 & $\mathrm{F}$ & $0.44(13)$ & $0.48(10)$ & $0.68(39)$ & $0.85(38)$ & - & - \\
\hline TS520 & APP/PS1 & $M$ & $1.43(20)$ & $0.73(20)$ & $1.20(20)$ & $0.88(20)$ & $2.40(10)$ & $1.98(14)$ \\
\hline TS526 & APP/PS1 & $F$ & $0.83(20)$ & $0.50(20)$ & $1.59(20)$ & $1.17(20)$ & $3.20(10)$ & $2.43(11)$ \\
\hline TS533 & APP/PS1 & $\mathrm{F}$ & $2.04(20)$ & $1.33(20)$ & $2.26(18)$ & $1.92(23)$ & $3.22(10)$ & $2.36(11)$ \\
\hline TS538 & APP/PS1 & $M$ & $1.39(20)$ & $0.57(20)$ & $1.78(20)$ & $1.37(20)$ & $2.36(11)$ & $2.17(11)$ \\
\hline TS546 & APP/PS1 & $M$ & $1.45(20)$ & $0.75(18)$ & $1.72(20)$ & $1.06(20)$ & $4.81(12)$ & $2.04(12)$ \\
\hline
\end{tabular}

\section{Human subjects}

Use of human tissue for post-mortem studies has been reviewed and approved by the Edinburgh Brain Bank ethics committee and the ACCORD medical research ethics committee, AMREC (ACCORD is the Academic and Clinical Central Office for Research and Development, a joint office of the University of Edinburgh and NHS Lothian, approval number 15-HV-016). The Edinburgh Brain Bank is a Medical Research Council funded facility with research ethics committee (REC) approval (11/ES/0022). Use of human stem cell derived neurons was approved by the NHS Lothian REC $(10 / \mathrm{S} 1103 / 10)$. 


\section{Western blots of human brain tissue}

The concentrations of protein samples from human brain whole homogenate preparations were measured via the bicinchoninic acid (BCA) assay (Micro BCA protein assay kit, ThermoFisher Scientific). $20 \mu \mathrm{g}$ of total protein were mixed 1:1 with Laemmli buffer and boiled at $95{ }^{\circ} \mathrm{C}$ for 10 minutes, and loaded to NuPAGE ${ }^{\mathrm{TM}} 4$ to $12 \%$, Bis-Tris gels. Gels were run at $120 \mathrm{~V}, 400 \mathrm{~mA},>2$ hours, until the loading dye ran to the bottom of the gel. Protein molecular ladder (Color Prestained Protein Standard, Broad Range 11-245 kDa, NEB, P7712S). Dry transfer was performed using an iBlot ${ }^{\mathrm{TM}} 2$ gel transfer device (Invitrogen) (8.5 minutes, $20 \mathrm{~V}$ ) onto a polyvinylidene difluoride (PVDF) membrane. Membranes were briefly washed in phosphate buffered saline (PBS) and then immersed in Revert ${ }^{\mathrm{TM}}$ 700 Total Protein Stain for 5 minutes at room temperature. Membranes were immediately washed in Revert 700 Wash Solution, exposed at $700 \mathrm{~nm}$ for 1 minute and imaged (Odyssey ${ }^{\oplus}$ FC, LICOR). Membranes were washed (Revert Destaining Solution) and blocked for 1 hour at room temperature (LICOR Blocking buffer mixed 1:1 with PBS enriched with 0.1\% Tween-20 in PBS-T). Membranes were incubated with primary antibody (anti-KCNC4; Alomone \#APC-019; 1:200) overnight at $4{ }^{\circ} \mathrm{C}$ in blocking buffer. Following $3 \times 10$-minute washes in PBS-T, membranes were incubated with horseradish peroxidase-conjugated (HRP) secondary antibodies (goat anti-rabbit-HRP; 1:5,000) in blocking buffer for 1 hour, at room temperature. Membranes were washed $3 \times 30$ minutes in PBS-T followed by incubation with Amersham ${ }^{\mathrm{TM}} \mathrm{ECL}^{\mathrm{TM}}$ Prime Western Blotting Detection Reagent (Cytiva) to visualise bands. Chemiluminescent bands were visualised using the LICOR Odyssey ${ }^{\circledR}$ Fc system. Tissue from nine donors was used for this study and their details are found in supplementary information. 


\begin{tabular}{|c|c|c|c|c|c|}
\hline & BBN & Sex & Age & PMI (hours) & Braak Stage \\
\hline \multirow{10}{*}{ 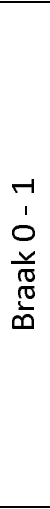 } & 001.35138 & $F$ & 73 & 74 & 0 \\
\hline & 001.34150 & $\mathrm{M}$ & 63 & 115 & 0 \\
\hline & 001.35420 & $F$ & 82 & 114 & I \\
\hline & 001.35215 & $M$ & 82 & 40 & I \\
\hline & 001.31504 & $\mathrm{~F}$ & 65 & 76 & $\mathrm{I}$ \\
\hline & 001.31503 & $\mathrm{~F}$ & 57 & 73 & I \\
\hline & 001.28402 & $M$ & 79 & 49 & $\mathrm{I}$ \\
\hline & 001.28794 & $\mathrm{~F}$ & 79 & 61 & $\mathrm{I}$ \\
\hline & 001.30208 & $M$ & 73 & 66 & $\mathrm{I}$ \\
\hline & 001.30178 & $M$ & 72 & 60 & 0 \\
\hline \multirow{10}{*}{$\begin{array}{l}+ \\
1 \\
m \\
\frac{1}{\pi} \\
\frac{\pi}{0} \\
0\end{array}$} & 001.32820 & $\mathrm{~F}$ & 69 & 94 & IV \\
\hline & 001.29528 & $\mathrm{~F}$ & 93 & 31 & III \\
\hline & 001.28411 & $\mathrm{~F}$ & 88 & 65 & III \\
\hline & 001.28405 & $M$ & 84 & 83 & IV \\
\hline & 001.26499 & $\mathrm{~F}$ & 81 & 59 & III \\
\hline & 001.26491 & $M$ & 77 & 27 & III \\
\hline & BBN_26492 & $\mathrm{F}$ & 74 & 71 & IV \\
\hline & BBN_24323 & $M$ & 67 & 103 & IV \\
\hline & BBN_20994 & $M$ & 75 & 59 & III \\
\hline & BBN_19600 & $\mathrm{F}$ & 85 & 36 & III \\
\hline \multirow{10}{*}{$\begin{array}{l}0 \\
1 \\
\sim \\
\frac{1}{\pi} \\
\frac{\pi}{0} \\
\frac{0}{0}\end{array}$} & 001.35183 & $M$ & 74 & 75 & VI \\
\hline & 001.35096 & $M$ & 72 & 103 & VI \\
\hline & 001.33698 & $\mathrm{~F}$ & 90 & 76 & VI \\
\hline & 001.33636 & $M$ & 93 & 43 & VI \\
\hline & 001.32929 & $\mathrm{~F}$ & 85 & 80 & VI \\
\hline & 001.30883 & $\mathrm{~F}$ & 61 & 69 & VI \\
\hline & 001.29911 & $M$ & 66 & 52 & VI \\
\hline & 001.29521 & $M$ & 95 & 96 & $\mathrm{VI}$ \\
\hline & 001.26500 & $M$ & 81 & 83 & VI \\
\hline & BBN_24668 & $\mathrm{F}$ & 96 & 61 & VI \\
\hline
\end{tabular}

Supplemental table 1: Human brain samples used for western blot analysis

\section{Human iPSC-derived cortical neuron culture}

We differentiated five iPSC lines from blood samples of healthy aged people participating in the Lothian Birth Cohort 1936 (LBC1936) study (Toombs et al., 2020). Briefly, peripheral blood mononuclear cells (PBMCs) were reprogrammed using non-integrating oriP/EBNA1 backbone plasmids expressing six iPSC reprogramming factors (OCT3/4 (POU5F1), SOX2, KLF4, L-Myc, shp53, Lin28, SV40LT). All lines demonstrated STR matched karyotype. Pluripotency was validated by immunocytochemistry, alkaline phosphatase staining, and Pluritest. Tri-lineage differentiation potential was confirmed by hPSC Scorecard and embryoid body formation techniques. All lines were 
confirmed to be mycoplasma negative. Tissue culture is conducted at $37^{\circ} \mathrm{C}, 5 \% \mathrm{CO}_{2}$. iPSCS are maintained in 6 well culture plates coated with 1:100 Geltrex and fed daily with Essential 8 (E8) media. iPSCs were passaged with 0.1\% EDTA pooled at a ratio of 5:1 in 6 well culture plates coated with 1:100 Geltrex and fed with E8 media. Differentiation into glutamatergic neurons was conducted by dual SMAD inhibition as described in (Supplemental figure 1 and (Shi et al., 2012)).

Generation of soluble human brain fraction was conducted according to a published protocol (W. Hong et al., 2018). Brain tissue was chopped and incubated for $30 \mathrm{~min}$ in artificial CSF (pH 7.4) supplemented with $1 x$ cOmplete mini EDTA-free protease inhibitor cocktail tablet (Roche, 11836170001). The was centrifuged at 2000 RCF for 10 mins to remove large, insoluble debris then centrifuged at 200,000 RCF for 110 mins. The resulting supernatant was dialyzed to remove salts and any drugs taken by the donor. The resulting homogenate was immunodepleted to remove soluble amyloid beta or mock immunodepleted using protein A agarose beads (Thermo, 20334) with 4G8 antibody (Biolegend, 800703) or mouse serum (Merck, M5905) as a mock condition (W. Hong et al., 2018). Concentration of $A \beta 1-42$ in $A \beta+$ and $A \beta$ - homogenate was quantified by sandwich ELISA (WAKO, 296-64401), according to manufacturer instructions. For experiments, $A \beta+$ homogenate was used at a final concentration of $15 \mathrm{pmol} / \mathrm{L}$. A $\beta$ - homogenate approximated the ELISA lower limit of quantification, therefore $A \beta$ content could not be accurately determined. $A \beta$-homogenate was diluted by the same factor as $A \beta+$, with a final concentration considered to be $<1 \mathrm{pmol} / \mathrm{L}$.

iPSC-derived cortical neurons were fixed with 4\% formalin (Polysciences, cat.04018-1) for 15 mins, rinsed in Dulbecco's phosphate buffered saline (D-PBS, Thermo 14190250) and stored in D-PBS at $4^{\circ} \mathrm{C}$ for up to a month before staining. To stain, coverslips containing fixed neurons were permeabilized and non-specific antigens blocked by incubating in D-PBS with $0.2 \%$ Triton-X (Merck, cat. $\mathrm{X} 100-500 \mathrm{ML}$ ) and $10 \%$ donkey serum (Merck, cat.566380-10ML) for one hour. Coverslips were incubated overnight at $4^{\circ} \mathrm{C}$ with primary antibodies: Homer (rabbit anti-Homer; Abcam; 1:500), MAP2 (guinea pig anti-MAP2; Synaptic Systems 188004; 1:1000), Kv3.4A (sheep anti-Kv3.4A; Autifony Ab101; $1: 100$ ) diluted in D-PBS containing $0.2 \%$ Triton-X and $1 \%$ donkey serum. Cells were then washed with D-PBS containing $0.1 \%$ Triton- $X$, and incubated in secondary antibodies diluted 1:500 in D-PBS containing $0.1 \%$ Triton-X and $1 \%$ donkey serum for one hour (donkey anti-rabbit-488 (Abcam ab150073), donkey anti-guinea pig-594 (Merck, SAB4600096), donkey anti-sheep647(Thermo A21448)). Coverslips were mounted on slides (VWR, 631-0847) with mounting media (Merck, cat.345789-20ML) and imaged on a Leica TCS confocal microscope with an oil immersion $63 x$ objective. Ten fields per coverslip containing MAP2 staining were randomly selected for imaging and image stacks acquired through the thickness of the cell layer $(0.3 \mu \mathrm{m}$ per step). Image stacks were processed using custom software to segment staining, calculate the density of synaptic 
markers along MAP2 positive processes, colocalization of $\mathrm{K}_{\mathrm{v}} 3.4$ with Homer 1 post-synaptic terminals, and measure the intensity of $K_{v} 3.4$ staining in dendrites. All image analysis scripts are freely available at https://github.com/Spires-Jones-Lab .

Aged neurons were incubated with Trizol (Thermo, 15596026) for five mins. Neurons were homogenised with a P200 pipette and collected in DNase/RNase free tubes (Eppendorf, 30108051). 200uL of chloroform (Sigma, 288306-100ML) was added per $1 \mathrm{~mL}$ Trizol sample and mixed by inversion. Samples were centrifuged at 12,000 RCF for 15 minutes at $4^{\circ} \mathrm{C}$. The aqueous phase containing RNA was collected and an equal volume of $100 \%$ isopropanol added. The sample was centrifuged at $12,000 \mathrm{RCF}$ for $10 \mathrm{mins}$ at $4^{\circ} \mathrm{C}$ and the supernatant discarded. The pellet was washed in two cycles of $0.5 \mathrm{~mL}$ of $70 \%$ ethanol and centrifugation at $12,000 \mathrm{RCF}$ for 10 mins at $4^{\circ} \mathrm{C}$. The sample was air dried for 10 mins at room temperature to evaporate any residual ethanol. The RNA pellet was solubilised in 30uL DEPC water (Thermo, AM9906) and transferred to a fresh DNase/RNase free Eppendorf, and stored at $-80^{\circ} \mathrm{C}$. Concentration and purity were measured using an LVis plate on a ClarioSTAR Plus spectrophotometer (BMG Labtech).

RT-qPCR was conducted using one-step RT-qPCR kit (Promega, A6020), according to manufacturer instructions. This product uses advanced BRYT green dye, enabling an RNA detection range of $500 \mathrm{fg}$ and up to $100 \mathrm{ng}$, and alleviates the need for prior cDNA translation. Briefly, 100ng RNA samples were added to a mastermix preparation (GoTaq qPCR Mastermix (2X), GoScript RT mix for 1-step RT-qPCR (50X), Forward Primer (200nM), Reverse Primer (200nM), and DEPC H2O) to a volume of $20 \mu \mathrm{L}$ per well. Primers are described in Supplementary table XX. RT-qPCr was conducted in a thermal cycler (BioRad, CFX96 Touch Real-Time PCR Detection System), with an initial denaturation step $\left(95^{\circ} \mathrm{C}, 10 \mathrm{mins}\right)$, then cyclic denaturation $\left(95^{\circ} \mathrm{C}, 10\right.$ seconds), annealing $\left(60^{\circ} \mathrm{C}, 30\right.$ seconds), and extension $\left(72^{\circ} \mathrm{C}, 30\right.$ seconds) for 40 cycles. This was concluded with a melt curve 65$95^{\circ} \mathrm{C}$. Data were analysed with BioRad CFX Maestro software. Target expression was normalised to that of two reference genes (GAPDH and RPLP1) using $\triangle \triangle C_{q}$ method. GAPDH and RPLP1 were determined to be the most stable reference genes of a gene panel tested on iPSC-neurons treated with $A \beta+$ and $A \beta$ - homogenate, with a Normfinder stability score of 0.09 .

\section{Data analysis}

Linear mixed effects models were used to analyse data with mouse as a random effect to account for multiple measurements per mouse. Genotype, treatment ( $\mathrm{K}_{\mathrm{v}} 3.4$ knockdown or control), sex, and plaque proximity (in APP/PS1 mice only) were fixed effects in mouse analyses. Assumptions of the model fit were tested by visual inspection of residual plots. Where needed, the data were transformed to better fit model assumptions (transformations noted in results). Analysis of variance tests were run on linear mixed effects models to examine main effects and estimated marginal 
means with Tukey corrections were used for post-hoc group comparisons. For spine morphology data, Pearson's chi-squared tests were used to compare all spines in each treatment group. For correlations with. Plaque distance, repeated measures correlations were conducted for each treatment group separately using a published package (Bakdash \& Marusich, 2017). All statistical analyses were run in R Studio and analysis scripts, data files analysed, and analysis outputs including residual plots and $\mathrm{Q}-\mathrm{Q}$ plots for models are provided as supplemental information. Data are presented as box plots of data from all images analysed with individual data points showing a mean for each mouse or human to show biological variability.

\section{Results}

To test the hypothesis that $\mathrm{K}_{\mathrm{v}} 3.4$ downregulation ameliorates dendritic spine loss associated with amyloid pathology, APP/PS1 mice and wildtype control mice were injected with an AAV containing the sgRNA targeting $\mathrm{K}_{\mathrm{v}} 3.4 / K C N C 4$ into neurons of their somatosensory cortex, thereby decreasing $K_{v} 3.4$ levels in this region. This AAV was co-injected with an AAV that introduced the gene for eYFP which allowed fluorescent visualisation of neurons. The contralateral hemisphere which was injected with an AAV to express the tdTomato reporter in cells served as a within-animal control condition. A total of 10 APP/PS1 mice and 6 wildtype mice were used in this study. The $K_{v} 3.4-k n o c k d o w n$ by AAV was assessed by measuring fluorescence intensity of $\mathrm{K}_{\mathrm{v}} 3.4$ staining in a subset of the animals used ( $n=5$ APP/PS1; $n=6$ WT mice). To examine synapse loss, dendrites labelled with eYFP/tdTomato were investigated in all mice, near $(0-30 \mu \mathrm{m})$ and far $(>30 \mu \mathrm{m})$ from plaques (if present), using confocal microscopy and measurements for dendritic spine density were produced using image stacks.

We observed a $21 \%$ decrease in $\mathrm{K}_{\mathrm{v}} 3.4$ staining intensity in eYFP-expressing neurons in which $\mathrm{K}_{\mathrm{v}} 3.4$ was knocked down compared to tdTomato-expressing control neurons (Figure 1, linear mixed effects model on Tukey transformed data followed by ANOVA, F[1,39.37]=38.22, $p<0.0001$ ). There was no significant effect of sex or genotype, nor was there an interaction between treatment and genotype. 

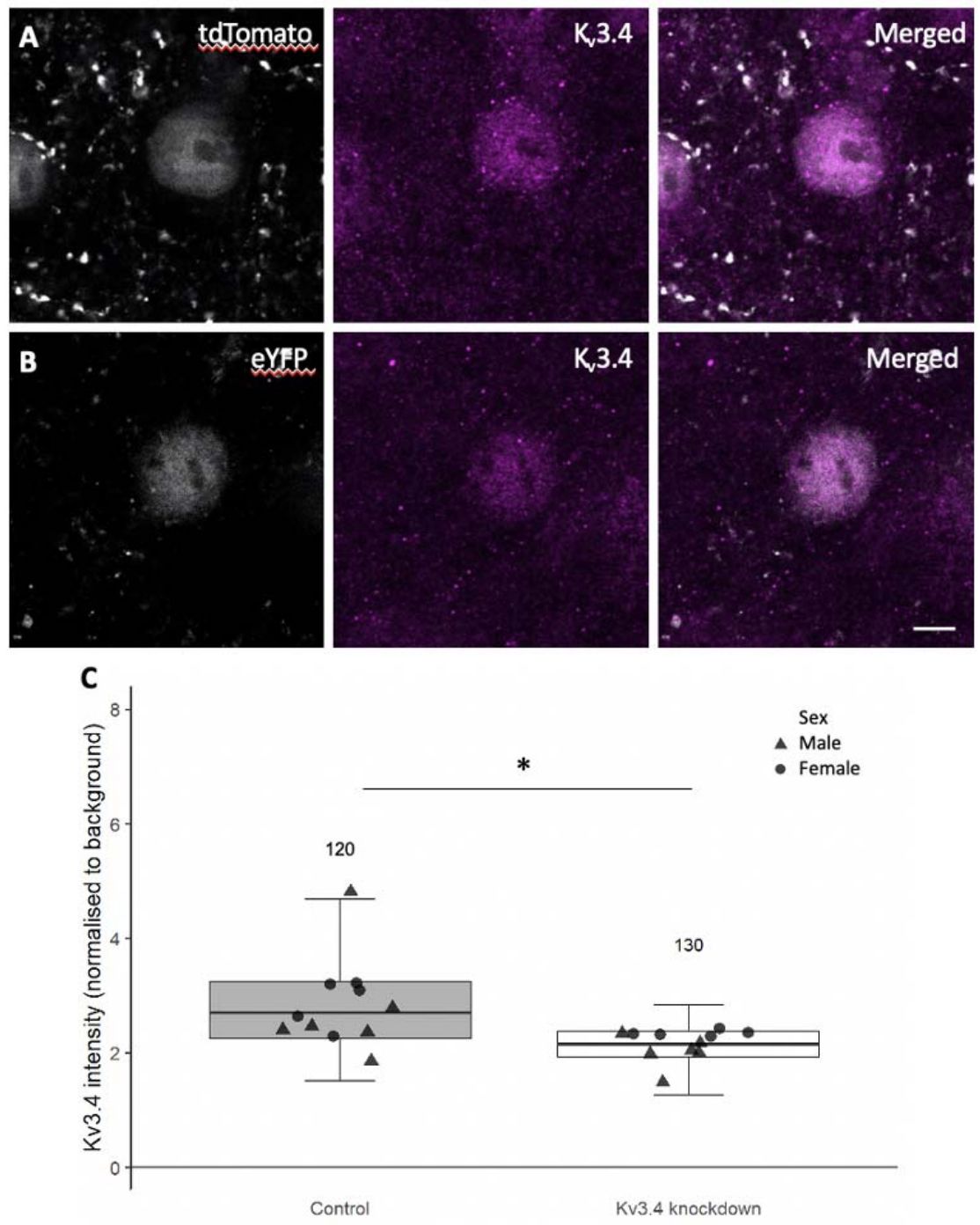

Figure 1. Representative immunostaining images of $K_{v} 3.4$ in neurons expressing either tdTomato or eYFP (A \& B). For comparison purposes, tdTomato and eYFP cell bodies are visualised in grey pseudocolour and Kv3.4 staining in magenta. Compared to the tdTomato-filled neuron, the eYFP-filled neuron shows lower $\mathrm{K}_{\mathrm{v}} 3.4$ immunoreactivity. Analysis of $\mathrm{K}_{\mathrm{v}} 3.4$ immunostaining intensity revealed a $21 \%$ reduction in staining intensity in eYFP-filled cells relative to tdTomato-filled cells (C), confirming the action of U6.sgRNA(mK $\left.\mathrm{v}_{\mathrm{v}} 3.4\right) . \mathrm{CMV}$.saCas9 at knocking down $\mathrm{K}_{\mathrm{v}} 3.4$ levels. ${ }^{*} \mathrm{p}<0.0001$ ANOVA effect of treatment; $\mathrm{N}$ above error bars represent number of cells analysed for each condition. Individual data point shows mean per mouse. Scale bar: $5 \mu \mathrm{m}$.

A reduction of dendritic spine density near plaques has been consistently reported in $A D$ mouse models, including APP/PS1 mice used in our current study (Koffie et al., 2009; Moolman et al., 2004; Rozkalne et al., 2011). Here, to analyse the effects of $K_{v} 3.4$ reduction on plaque associated spine loss, we measured dendritic spine density of dendrite branches from layer II, III and V originating from cortical pyramidal neurons filled with eYFP/tdTomato in APP/PS1 and control mice (Figure 2A-F). In general, the spine density in APP/PS1 transgenic mice was significantly lower 
compared to wildtype mice (Figure $3 \mathrm{~A}, \mathrm{~F}[1,13.06]=16.20, \mathrm{p}=0.001$ ). Under control conditions, dendrites in APP/PS1 mice had significantly less spines than those in wildtype mice $(\beta=0.85, t=3.52$, $p=0.012$, post-hoc estimated marginal means comparison), which is in accord with previous studies (Koffie et al., 2009; Moolman et al., 2004; Rozkalne et al., 2011). There is further a positive correlation between plaque distance and spine density in the tdTomato filled control dendrites of APP/PS1 mice (Figure 3C, repeated measures correlation $r_{r m}=0.14, d f=221,95 \% \mathrm{Cl}$ 0.014-0.272, $p=0.03$ ), which was absent in their eYFP filled $K_{v} 3.4-k n o c k d o w n$ dendrites (Figure $3 C, r=0.095$, $d f=245$, $95 \% \mathrm{Cl}-0.031-0.271, \mathrm{p}=0.14)$.

$K_{v} 3.4$ downregulation evidently increased spine density compared to the control hemisphere in both APP/PS1 and wildtype mice (Figure 3A, treatment effect $F[1,1102.12]=163.29, p<0.0001$ ) by $36.3 \%$ and $23.2 \%$, respectively, with a bigger effect recorded in wildtype mice (Genotype $x$ treatment interaction $F[1,1102.12]=17.86, p<0.0001)$. Importantly, $K_{v} 3.4$ reduction in APP/PS1 mice restored spine density to be not significantly different from WT control level, as confirmed by post-hoc estimated marginal means comparisons (Figure 3A).

In APP/PS1 mice, dendrites within $30 \mu \mathrm{m}$ of a plaque edge had lower spine densities than those farther away in both conditions (Figure 3B, effect of plaque proximity $F[1,867.22]=172.88$, $\mathrm{p}<0.0001$ ). In comparison to the control condition, $\mathrm{K}_{\mathrm{v}} 3.4$ knockdown significantly increased spine densities (effect of treatment, $F[1,867.42]=94.15, p<0.0001$ ) by $32.7 \%$ in dendrites far from plaques ( $t=-5.78, p<0.001$ post-hoc comparison) and by $26.4 \%$ in dendrites near plaques $(t=-8.59$, $p<0.0001$ ). This rescue of plaque-associated spine loss with $K_{v} 3.4$ knockdown is also illustrated when spine density is plotted versus plaque distance (Figure $3 \mathrm{C}$ ).

In addition to spine densities, we also examined dendritic spine morphology, which affects postsynaptic integration of signals. There is a differential distribution of spine shapes in the control hemisphere of APP/PS1 mice with 7x more stubby spines compared to WT control level (Figure 3E, $\chi^{2}$ $p<0.05$ and $\chi^{2}$ Bonferroni adjusted post-hoc test $p<0.05$ ). $K_{v} 3.4$ knockdown reduces the number of stubby spines by more than half in these APP/PS1 mice (Figure $3 E$ ), which is also reflected in Figure $3 \mathrm{~F}$, where dendrites in both hemisphere conditions were further classified according to their plaque proximity. For dendrites distant from plaques and near plaques, the decrease in stubby spines in $\mathrm{K}_{\mathrm{v}} 3.4$ knockdown hemisphere relative to control hemisphere appears to be accompanied by a compensatory increase in the proportion of thin spines, but neither of these changes reached significance (Figure 4B). 


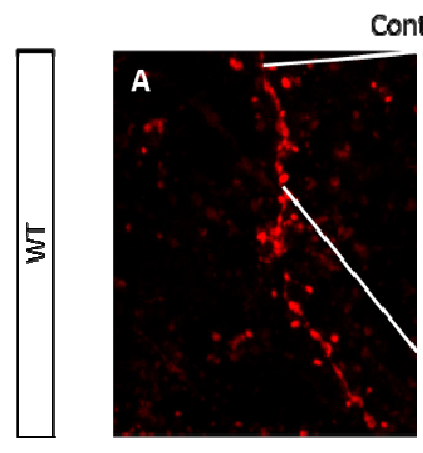

Control
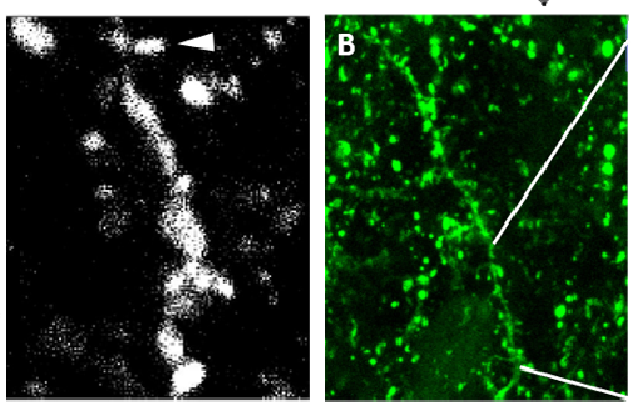

K.3.4 knockdown
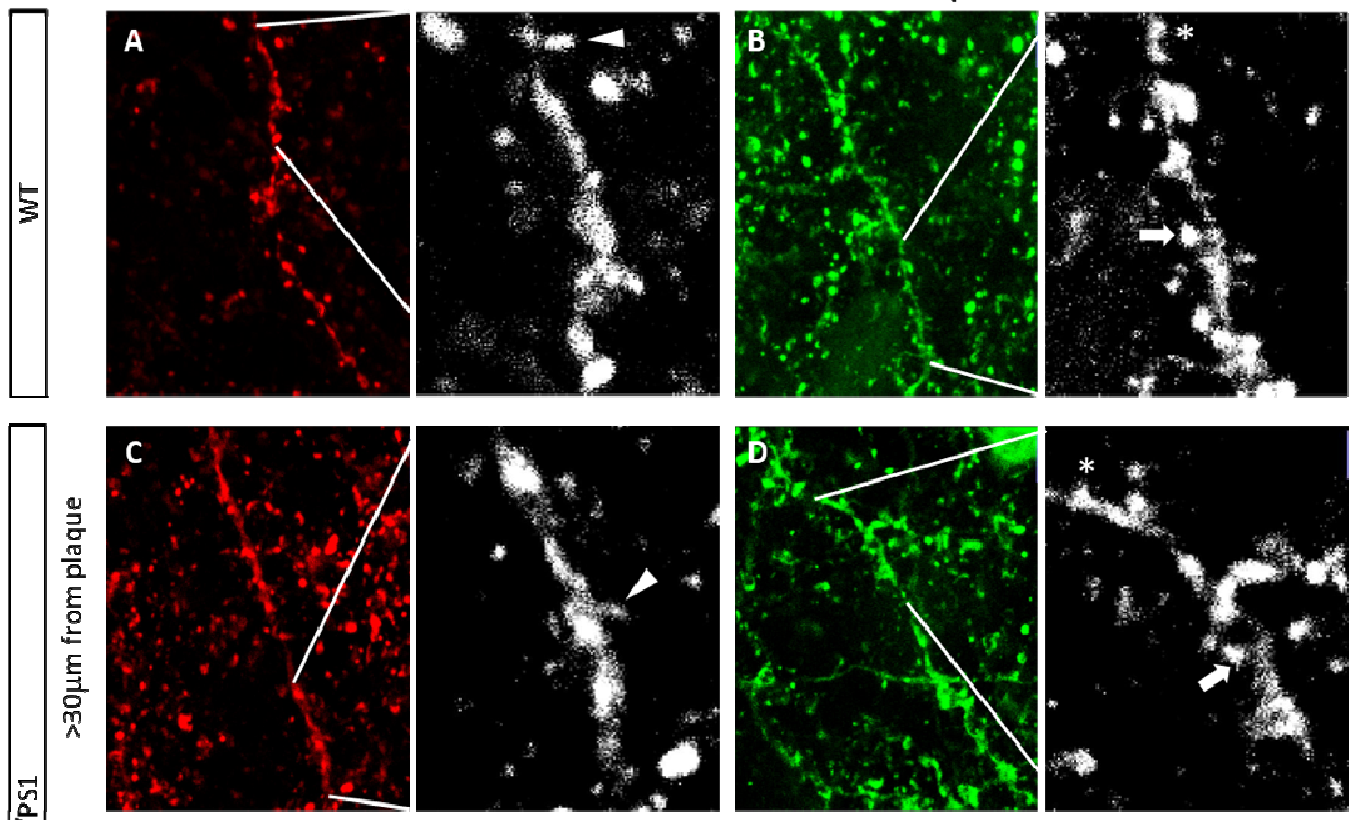

$\frac{\sum_{0}^{\circ}}{4}$
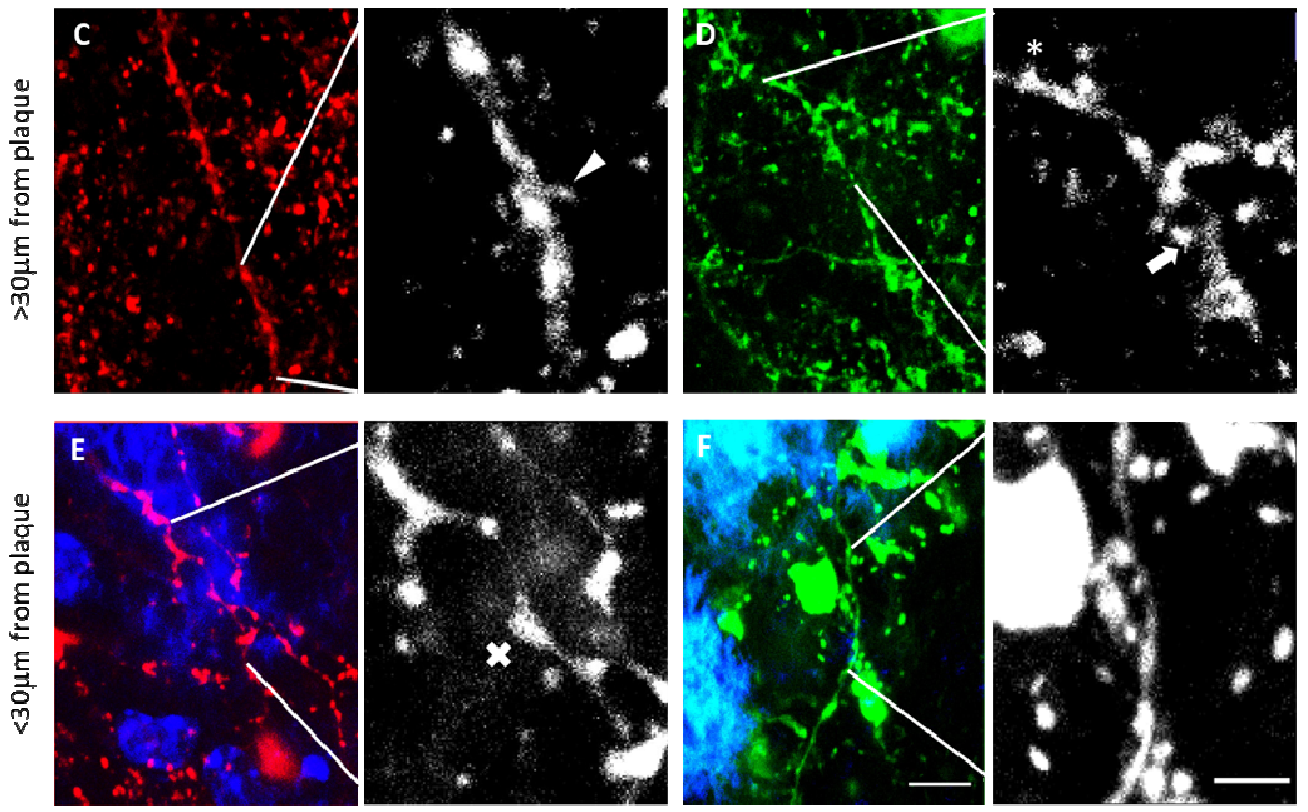

Figure 2. Dendritic spines were examined on dendrites from cortical pyramidal neurons filled with tdTomato or eYFP under control ( $A, C$ \& $E$ ) or $K_{v} 3.4$ knockdown conditions ( $B, D$ \& $F$ ), respectively. Spines were classified by shape as either mushroom (arrows), thin (arrowheads) or stubby (asterisks) based on the head to neck diameter ratio. Senile plaques in APP/PS1 mice were labelled in blue using ThioS (E \&F). There is visible focal swelling (crosses) of dendritic segments that are in close proximity to plaques (E \& F). Images are shown as maximum intensity Z-projections of 9 serial confocal images. Scale bar: $5 \mu \mathrm{m}$ (left); $2 \mu \mathrm{m}$ (right). 
A
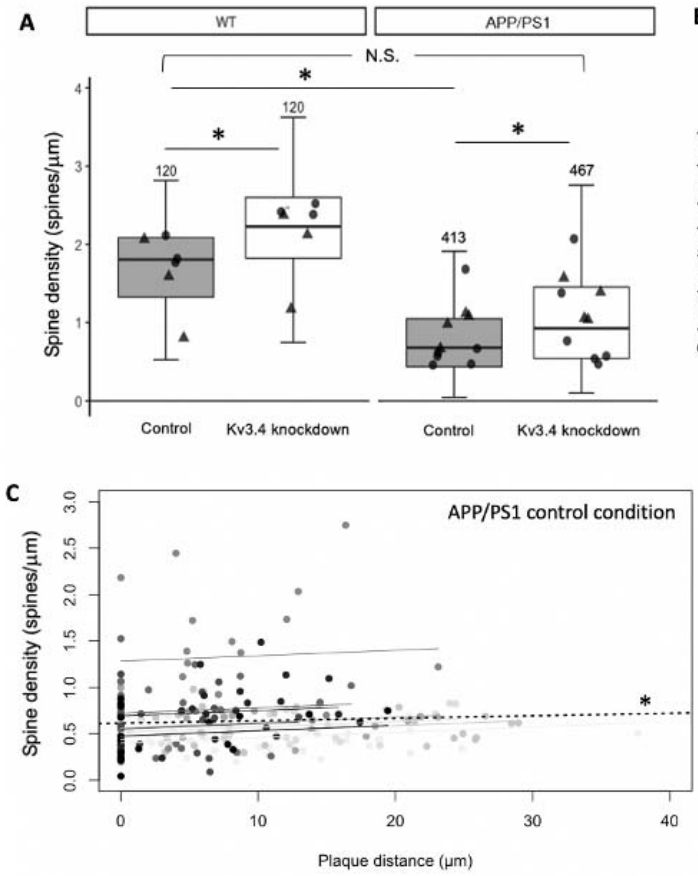

E

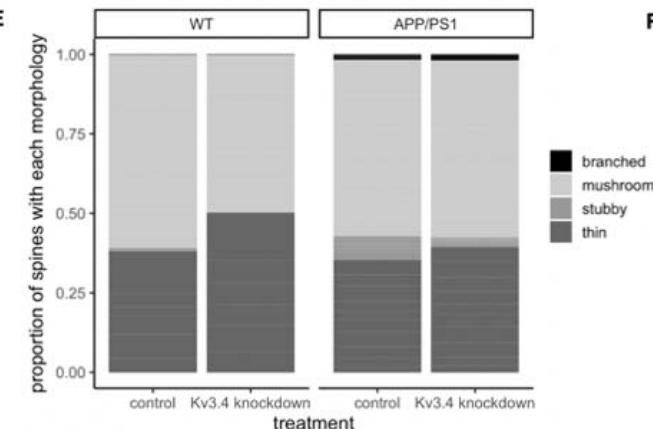

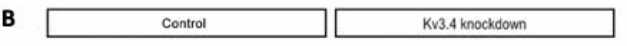
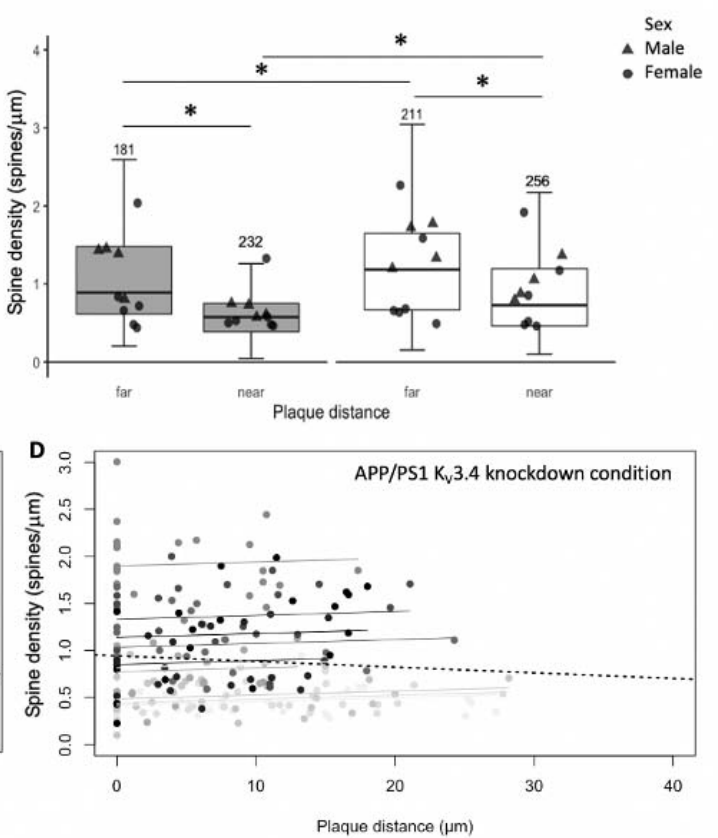

F

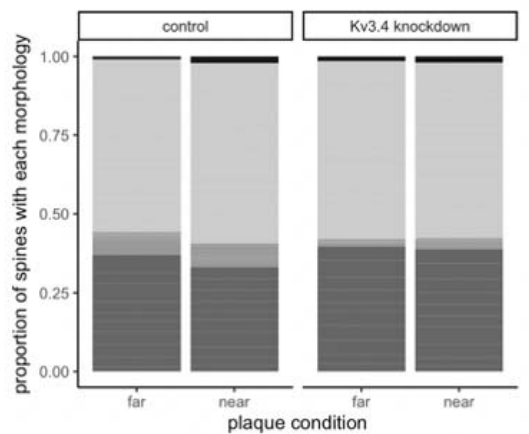

Figure 3. Under control conditions, there is a $62.4 \%$ reduction in spine density in APP/PS1 mice compared to WT mice without the APP and PS1 transgenes (A). $K_{v} 3.4$ knockdown increases spine densities in both wildtype (WT) and APP/PS1 mice relative to control conditions, and restores spine densities in the transgenic mice to near WT control levels. In APP/PS1 mice, lower spine densities were recorded in dendrites within $30 \mu \mathrm{m}$ of plaques in contrast to those distant from plaques $(B)$. $\mathrm{K}_{\mathrm{v}} 3.4$ downregulation improved spine densities in all dendrites measured in APP/PS1 mice $(A, B$ ${ }^{*} p<0.05$, pot-hoc estimated marginal means comparisons with Tukey correction. $N$ above error bars represent number of dendrites analysed for each condition. Individual data point shows mean per mouse). Under control conditions, spine density of APP/PS1 mice correlated with distance from the nearest plaque ( $C, * p=0.03$ repeated measures correlation). This correlation was absent in the $\mathrm{K}_{\mathrm{v}} 3.4$ knockdown dendrites, indicating that $\mathrm{K}_{\mathrm{v}} 3.4$ knockdown is protective (D). In $C$ and $\mathrm{D}$ data points show individual dendrites shaded to show those from each individual mouse, the regression line for each mouse is shown in the same shade, and the overall regression is the black dotted line. The control hemisphere of APP/PS1 mice shows a shift in spine morphology to favour stubby spines $\left(E, \chi^{2}=18.15, p=0.03\right.$, Bonferroni adjusted post-hoc test), which was ameliorated by $\mathrm{K}_{\mathrm{v}} 3.4$ knockdown both compared to wild-type mice (E) and near and far from plaques (F). Values are reported as the proportion of spines in each category generated from means per mouse. 
To determine whether the rescue observed in our transgenic mouse line may be relevant to human brain, we examined $\mathrm{K}_{\mathrm{v}} 3.4$ in human post-mortem brain samples and human iPSC-derived neuronal cultures. In human iPSC neurons derived from blood samples from 5 different donors, we observe $\mathrm{K}_{\mathrm{v}} 3.4$ in synapses along dendrites (Figure 4), demonstrating the presence of $\mathrm{K}_{\mathrm{v}} 3.4$ protein in human synapses. Interestingly, challenging these neurons with human AD brain homogenate causes a decrease in $\mathrm{K}_{\mathrm{v}} 3.4$ expression alongside an increase in curvature of MAP2 positive neurites (Figure 5, ANOVA of linear mixed effects model of data transformed with the formula(Tortuosity-1) $\wedge 1 / 7$ to fit assumptions of model: $F[1,6944]=15.21, p<0.0001)$. In human brain from people with very low (Braak 0-I), moderate (Braak III-IV) and extensive (Braak V-VI) Alzheimer's disease pathology, we confirm that $K_{v} 3.4$ is expressed in both frontal and temporal cortices (Brodmann areas 9 and 20/21, respectively). In our samples, we do not observe any difference in levels between Braak stages or brain regions (linear model with Braak stage group, brain region, age, sex, and post-mortem interval as fixed effects: effect of Braak stage group $F[2,50]=0.092, p=0.91$; effect of brain region $F[1,50]=0.626, p=0.43$, data Tukey transformed to meet assumptions of linear model). There were also no effects of sex, age or PMI in our analyses (Supplemental Figure 1). 
bioRxiv preprint doi: https://doi.org/10.1101/2021.11.24.469829; this version posted November 25, 2021. The copyright holder for this preprint (which was not certified by peer review) is the author/funder, who has granted bioRxiv a license to display the preprint in perpetuity. It is made available under aCC-BY 4.0 International license.

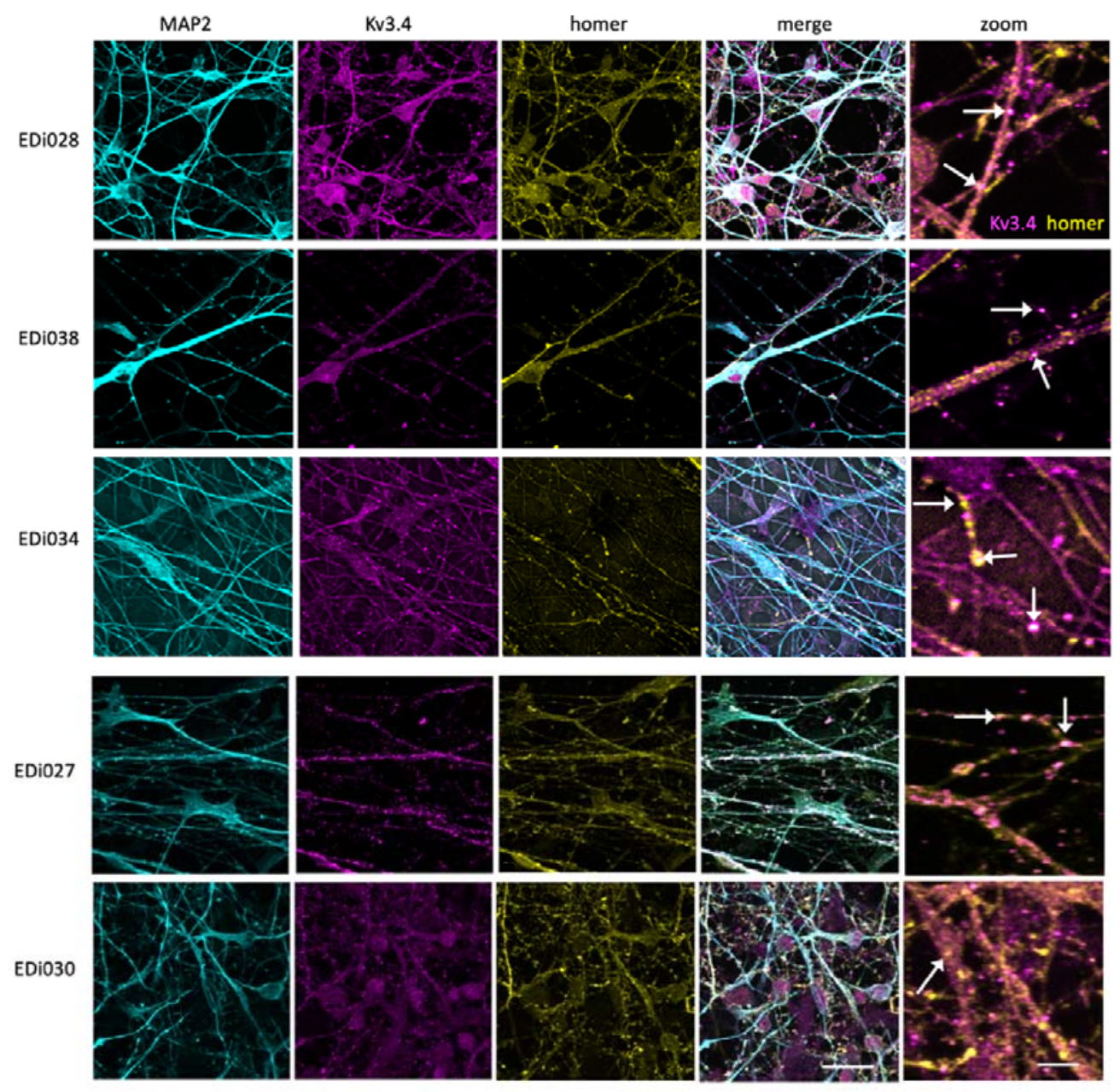

Figure 4. iPSC-derived cortical neurons from 5 human donors (lines EDi027, EDi028, EDi030, EDi034, EDi038) stained with MAP2 to label dendrites (cyan), postsynaptic protein homer 1 (yellow) and $\mathrm{K}_{\mathrm{v}} 3.4$ (magenta), have $\mathrm{K}_{\mathrm{v}} 3.4$ positive synaptic puncta along dendrites (arrows in zoom). Scale bar represents $20 \mu \mathrm{m}$ ( $5 \mu \mathrm{m}$ in zoom on right column). 
A

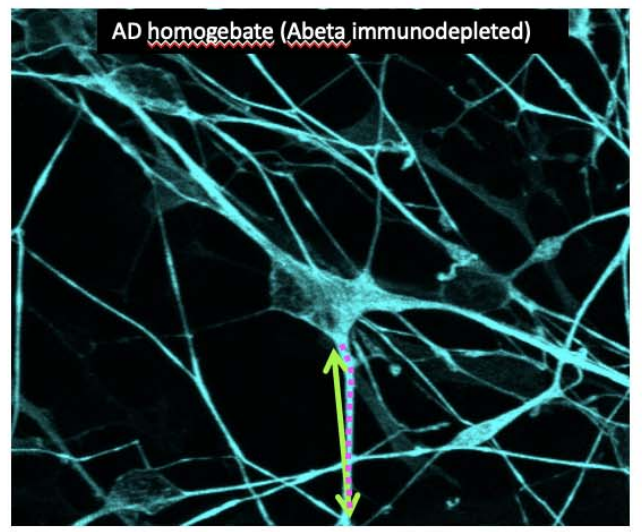

B

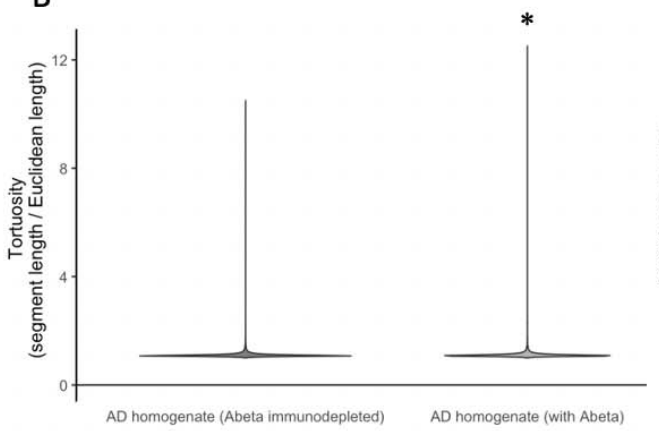

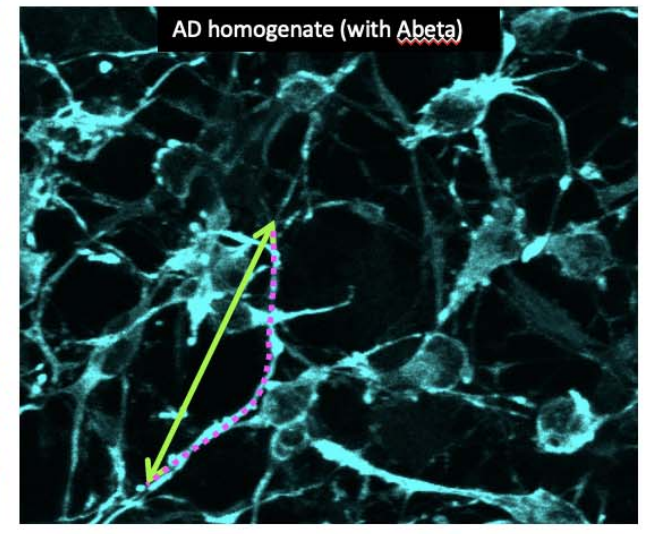

C

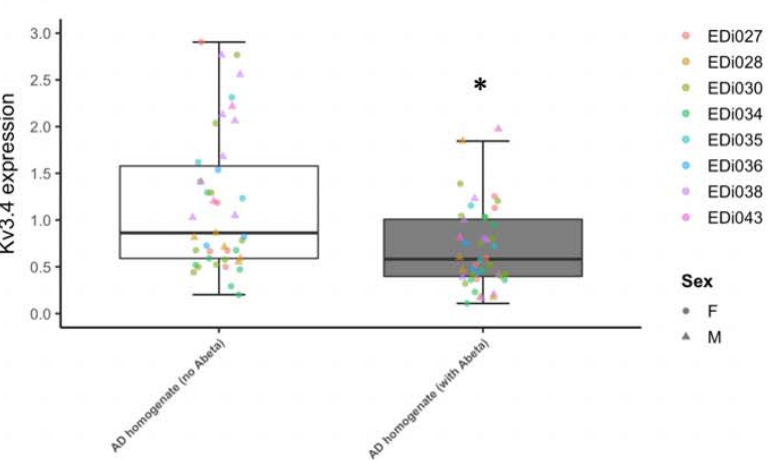

Figure 5: Human iPSC derived neurons were challenged with homogenate of brain from AD patients either mock immunodepleted for amyloid beta (Abeta) or immunodepleted to remove toxic Abeta. These neurons were fixed and stained for dendrites (MAP2, cyan) and dendrite tortuosity was measured as the dendritic segment length (magenta dotted line) divided by the direct Euclidean distance between the ends of the segment (green arrows, A). A violin plot of tortuosity shows an increase in curvature of dendrites treated with $A \beta$ containing $A D$ brain homogenate ( $B,{ }^{*}$ ANOVA on linear mixed effects model of transformed data with experiment and image nested in line as a random effect, $F[1,6944]=14.21, p<0.0001)$. AD brain homogenate also causes a decrease in Kv3.4 expression as measured by $\mathrm{qPCR}(\mathrm{C}$, * ANOVA on linear mixed effects model with experiment nested in line as a random effect, $F[1,47]=25.55, p<0.0001$ ). Scale bars represent $20 \mu \mathrm{m}$ in $A$ and $5 \mu \mathrm{m}$ in $B$. 

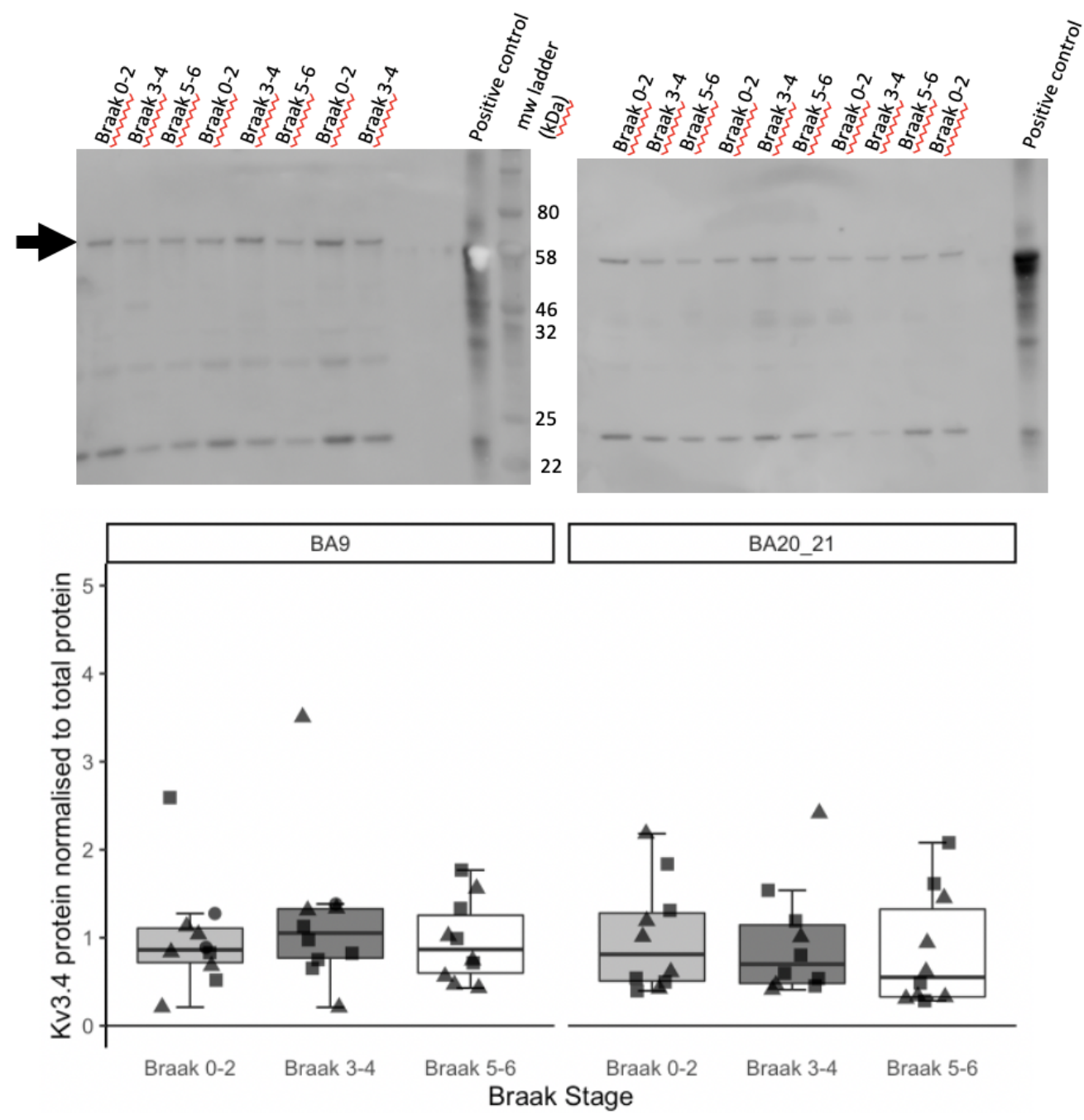

Supp Fig 1: Western blot of human brain samples from frontal (BA9) and temporal (BA20/21) cortex of people with low (Braak 0-2), moderate (Braak 3-4) and extensive (Braak 5-6) Alzheimer's disease pathology reveals no difference between brain regions or Braak stages ( $n=10$ per group, linear model on Tukey transformed data $\mathrm{p}>0.05$ for all fixed effects). The arrow indicates full-length $\mathrm{K}_{\mathrm{v}} 3.4$ protein immunoreactivity.

\section{Discussion}

The loss of synapses has implications for the impaired learning and memory in Alzheimer's patients considering the strong correlation between synapse loss and cognitive decline in disease (DeKosky et al., 1996; DeKosky \& Scheff, 1990; Terry et al., 1991). Further the plasticity of synapses and ability to target synaptic receptors makes them attractive therapeutic targets. Based on previous data showing elevated expression of $K_{v} 3.4$ around $A \beta$ plaques in human $A D$ brain and in model systems (Angulo et al., 2004; Boscia et al., 2017; Pannaccione et al., 2007), here we tested the hypothesis that $K_{v} 3.4$ is involved in synapse loss in the APP/PS1 mouse model of amyloidopathy. Previous work 
using $\mathrm{K}_{\mathrm{v}} 3.4$ downregulation, either through siRNA or a selective toxin blocker, has shown neuroprotective effects in hippocampal cultures and in Tg2576 mice (Boscia et al, 2017; Ciccone et al, 2019; Pannaccione et al, 2007). In this study, we observed that the downregulation of $\mathrm{K}_{\mathrm{v}} 3.4$ using CRISPR/Cas9 AAV ameliorates plaque-associated dendritic spine loss in APP/PS1 mice. Upon examination of cortical pyramidal neurons, we found dendritic spine loss in APP/PS1 mice which is exacerbated near plaques, in agreement with previous findings in several different plaque-bearing transgenic mice (Koffie et al., 2009; Moolman et al., 2004; Rozkalne et al., 2011; Spires, 2005). $\mathrm{K}_{\mathrm{v}} 3.4$ knockdown rescues this phenotype in APP/PS1 mice, restoring spine density to wildtype control levels. Given their ability to impact membrane depolarisation and neurotransmitter release it certainly anticipated that the fine control of potassium (and indeed other) channel expression at synapses will act as a regulator of synaptic activity in several brain regions. Dendritic spines make up the postsynaptic element of over $90 \%$ of cortical excitatory synapses, thus our findings indicate that $\mathrm{K}_{\mathrm{v}} 3.4$ downregulation alleviates synapse loss in plaque-bearing mice. Although we did not replicate published findings (Angulo et al 2004) showing increased $K_{v} 3.4$ levels in human AD brain compared to controls, we do observe $\mathrm{K}_{\mathrm{v}} 3.4$ specifically localised to synapses in human iPSC-derived cortical neurons, supporting the possibility that $K_{\mathrm{v}} 3.4$ in human synapses may mediate $A \beta$-induced synaptotoxicity.

One potential mechanism linking $A \beta$ to $K_{v} 3.4$ is that oligomeric $A \beta$ promotes the generation of $\mathrm{Ca}^{2+}$-induced reactive oxygen species (ROS) and activates the transcriptional factor nuclear factor kappa-B (NF-KB) that in turn upregulates $\mathrm{K}_{\mathrm{v}} 3.4$ gene expression. The upregulated expression of $\mathrm{K}_{\mathrm{v}} 3.4$ mediates excessive $\mathrm{K}^{+}$efflux, leading to the activation of caspase-3 (Piccialli et al, 2020). Caspase-3 has been implicated in spine degeneration and consequent synaptic failure ( $D^{\prime}$ Amelio et al., 2011) as well as to the accumulation of tau in neurofibrillary tangles (de Calignon et al., 2010; Spires-Jones et al., 2008). Caspase-3 activated calcineurin has been shown to drive the internalisation of $\alpha$-Amino-3hydroxy-5-methyl-4-isoxazolepropionic acid (AMPA) receptors from postsynaptic sites, and this is sufficient to cause spine elimination and the loss of synaptic NMDA receptors (D'Amelio et al., 2011; Hsieh et al., 2006; Snyder et al., 2005). Our previous work in mouse models has demonstrated that lowering calcineurin levels is also protective against dendritic spine loss in mouse models (Rozkalne et al., 2011; Wu et al., 2010). Elevated ROS production, NF-KB activity and $\mathrm{K}^{+}$efflux are also prerequisites for the formation of microglial and astrocytic inflammasomes (Venegas \& Heneka, Michael, 2019), and data are accumulating linking both microglia and astrocytes to synapse loss in AD models (Henstridge et al., 2019; S. Hong et al., 2016; Litvinchuk et al., 2018). It is also noteworthy that Kv3.4 is expressed in astrocytes in addition to neurones where it is upregulated in models of $A D$ (Boscia et al 2017). Hence a direct impact of Kv3.4 downregulation on the reactive astrocytes in the 
AD brain may also deliver an additional and useful benefit alongside the impact on neuronal synaptic health quantified in detail here. Another potential explanation for the spine density recovery observed in our APP/PS1 mice is that reducing $\mathrm{K}_{\mathrm{v}} 3.4$ may have an effect on synapses independent of $A \beta$. This is supported by. Our data showing that knockdown of $K_{v} 3.4$ also increased spine density in WT mice.

In addition to the impact on synapse density, we also observed changes in the proportion of specific spine types, noting a clear increase in the number of stubby spines in APP/PS1 mice. This observation has been reported in numerous studies using cortical biopsies from AD patients, and transgenic mice carrying a familial-AD associated mutant APP transgene (Androuin et al., 2018; Spires-Jones et al., 2007; Tackenberg \& Brandt, 2009). Studies in hippocampal cultures as well as in vivo in mice further revealed a gradual change from mushroom to stubby spines upon $A \beta$ (Penazzi et al., 2016), highlighting the impact of $A \beta$ on dendritic spine dynamics. While stubby spines are suggested to be the morphological correlate of LTD induction downstream of A $\beta$ (Li et al., 2009), the loss of mushroom spines is seen as a morphological marker for synaptic failure (Tackenberg \& Brandt, 2009). The increase in stubby spines without significant changes in mushroom spines observed our current study has also been documented in a recent hippocampal slice culture study with acute $A \beta$ treatment (Ortiz-Sanz et al., 2020). In contrast to mature mushroom spines that form strong synaptic connections, stubby spines are immature, more dynamic and relatively scarce in the mature brain (Fiala et al., 1998; Harris et al., 1992). Spine outgrowth and maturation are dependent on NMDA and AMPA receptors (Engert \& Bonhoeffer, 1999; Matus, 2000). Assuming that the spine loss detected in our APP/PS1 mice was a result of caspase-3 induced AMPA receptor endocytosis, the resulting loss of both AMPA and NMDA receptors may explain the increased number of immature stubby spines in our transgenic mice. Fundamentally, changes in spine morphology affect the postsynaptic integration of signals. While the volume of the spine head is important for the expressions of NMDA and AMPA receptors (Matsuzaki et al., 2001, 2004), the spine neck is responsible for $\mathrm{Ca}^{2+}$ compartmentalisation (Grunditz et al., 2008). $\mathrm{Ca}^{2+}$ imaging studies demonstrated a drastic increase in accumulated $\mathrm{Ca}^{2+}$ at the base of short stubby spines devoid of a neck (Noguchi et al., 2005). This would permit such a copious amount of $\mathrm{Ca}^{2+}$ to enter the parent dendrite that causes a loss of spineto-dendrite $\mathrm{Ca}^{2+}$ homeostasis, as observed through $\mathrm{Ca}^{2+}$ imaging in APP/PS1 mice (Kuchibhotla et al., 2008). Our observation that $K_{v} 3.4$ knockdown shifts spine morphology from stubby to thin in APP/PS1 mice is interesting as thin spines become less prevalent alongside age-related cognitive deterioration in monkeys (Dumitriu et al., 2010). Thin spines are thought to be "learning spines" that are capable of strengthening plasticity in the local circuit (Bourne \& Harris, 2007). Thus, the potential of targeting $\mathrm{K}_{\mathrm{v}} 3.4$ to increase the proportion of thin spines in $A D$ may also result in restored plasticity 
and cognitive benefits, as reported in the $17 \beta$-estradiol treatment study that targets spine dynamics in rhesus monkeys (Hao et al., 2006).

Taken together, our results demonstrate that $\mathrm{K}_{\mathrm{v}} 3.4$ downregulation is able to reduce dendritic spine loss and restore spine density and morphology in aged APP/PS1 mice. We also observe $\mathrm{K}_{\mathrm{v}} 3.4$ expression on the synapses of human neurons making it a promising target for the development of novel therapeutic agents that seek to modulate Kv3.4 expression and/or function for the treatment of Alzheimer's disease, and potentially other CNS diseases.

\section{Acknowledgements}

This work was funded by Autifony Therapeutics Ltd, Alzheimer's Research UK (ARUK-TVPG2018-010), the UK Dementia Research Institute, which receives its funding from DRI Ltd, funded by the UK Medical Research Council, Alzheimer's Society, and Alzheimer's Research UK, and the European Research Council (ERC) under the European Union's Horizon 2020 research and innovation programme under grant agreement No 681181, and NIH grant R56-AG072473 (M.J.M.R.), and the

Emory Alzheimer's Disease Research Center Grant 00100569 (M.J.M.R.).

\section{Declaration of conflicts of interest}

TSJ received funding from Autifony Therapeutics Ltd and an anonymous industry partner and is on the Scientific Advisory Board of Cognition Therapeutics.

\section{References}

Androuin, A., Potier, B., Nägerl, U. V., Cattaert, D., Danglot, L., Thierry, M., Youssef, I., Triller, A., Duyckaerts, C., El Hachimi, K. H., Dutar, P., Delatour, B., \& Marty, S. (2018). Evidence for altered dendritic spine compartmentalization in Alzheimer's disease and functional effects in a mouse model. Acta Neuropathologica, 135(6), 839-854. https://doi.org/10.1007/s00401018-1847-6

Angulo, E., Noé, V., Casadó, V., Mallol, J., Gomez-Isla, T., Lluis, C., Ferrer, I., Ciudad, C. J., \& Franco, R. (2004). Up-regulation of the Kv3.4 potassium channel subunit in early stages of Alzheimer's disease. Journal of Neurochemistry, 91(3), 547-557. https://doi.org/10.1111/j.14714159.2004.02771.x

Bakdash, J. Z., \& Marusich, L. R. (2017). Repeated Measures Correlation. Frontiers in Psychology, 8, 456. https://doi.org/10.3389/fpsyg.2017.00456

Boscia, F., Pannaccione, A., Ciccone, R., Casamassa, A., Franco, C., Piccialli, I., de Rosa, V., Vinciguerra, A., Di Renzo, G., \& Annunziato, L. (2017). The expression and activity of KV3.4 channel subunits are precociously upregulated in astrocytes exposed to $A \beta$ oligomers and in astrocytes of Alzheimer's disease Tg2576 mice. Neurobiology of Aging, 54, 187-198. https://doi.org/10.1016/j.neurobiolaging.2017.03.008

Bourne, J., \& Harris, K. M. (2007). Do thin spines learn to be mushroom spines that remember? Current Opinion in Neurobiology, 17(3), 381-386. https://doi.org/10.1016/j.conb.2007.04.009 
Ciccone, R., Piccialli, I., Grieco, P., Merlino, F., Annunziato, L., \& Pannaccione, A. (2019). Synthesis and Pharmacological Evaluation of a Novel Peptide Based on Anemonia sulcata BDS-I Toxin as a New KV3.4 Inhibitor Exerting a Neuroprotective Effect Against Amyloid- $\beta$ Peptide. Frontiers in Chemistry, 7, 479. https://doi.org/10.3389/fchem.2019.00479

Colom-Cadena, M., Spires-Jones, T., Zetterberg, H., Blennow, K., Caggiano, A., DeKosky, S. T., Fillit, H., Harrison, J. E., Schneider, L. S., Scheltens, P., de Haan, W., Grundman, M., van Dyck, C. H., Izzo, N. J., Catalano, S. M., \& Synaptic Health Endpoints Working Group. (2020). The clinical promise of biomarkers of synapse damage or loss in Alzheimer's disease. Alzheimer's Research \& Therapy, 12(1), 21. https://doi.org/10.1186/s13195-020-00588-4

D'Amelio, M., Cavallucci, V., Middei, S., Marchetti, C., Pacioni, S., Ferri, A., Diamantini, A., De Zio, D., Carrara, P., Battistini, L., Moreno, S., Bacci, A., Ammassari-Teule, M., Marie, H., \& Cecconi, F. (2011). Caspase-3 triggers early synaptic dysfunction in a mouse model of Alzheimer's disease. Nature Neuroscience, 14(1), 69-76. https://doi.org/10.1038/nn.2709

de Calignon, A., Fox, L. M., Pitstick, R., Carlson, G. A., Bacskai, B. J., Spires-Jones, T. L., \& Hyman, B. T. (2010). Caspase activation precedes and leads to tangles. Nature, 464(7292), 1201-1204. https://doi.org/10.1038/nature08890

DeKosky, S. T., \& Scheff, S. W. (1990). Synapse loss in frontal cortex biopsies in Alzheimer's disease: Correlation with cognitive severity. Annals of Neurology, 27(5), 457-464. https://doi.org/10.1002/ana.410270502

DeKosky, S. T., Scheff, S. W., \& Styren, S. D. (1996). Structural correlates of cognition in dementia: Quantification and assessment of synapse change. Neurodegeneration: A Journal for Neurodegenerative Disorders, Neuroprotection, and Neuroregeneration, 5(4), 417-421. https://doi.org/10.1006/neur.1996.0056

Dumitriu, D., Hao, J., Hara, Y., Kaufmann, J., Janssen, W. G. M., Lou, W., Rapp, P. R., \& Morrison, J. H. (2010). Selective changes in thin spine density and morphology in monkey prefrontal cortex correlate with aging-related cognitive impairment. The Journal of Neuroscience: The Official Journal of the Society for Neuroscience, 30(22), 7507-7515. https://doi.org/10.1523/JNEUROSCl.6410-09.2010

Engert, F., \& Bonhoeffer, T. (1999). Dendritic spine changes associated with hippocampal long-term synaptic plasticity. Nature, 399(6731), 66-70. https://doi.org/10.1038/19978

Fiala, J. C., Feinberg, M., Popov, V., \& Harris, K. M. (1998). Synaptogenesis Via Dendritic Filopodia in Developing Hippocampal Area CA1. Journal of Neuroscience, 18(21), 8900-8911. https://doi.org/10.1523/JNEUROSCI.18-21-08900.1998

Grunditz, A., Holbro, N., Tian, L., Zuo, Y., \& Oertner, T. G. (2008). Spine neck plasticity controls postsynaptic calcium signals through electrical compartmentalization. The Journal of Neuroscience: The Official Journal of the Society for Neuroscience, 28(50), 13457-13466. https://doi.org/10.1523/JNEUROSCI.2702-08.2008

Hao, J., Rapp, P. R., Leffler, A. E., Leffler, S. R., Janssen, W. G. M., Lou, W., McKay, H., Roberts, J. A., Wearne, S. L., Hof, P. R., \& Morrison, J. H. (2006). Estrogen alters spine number and morphology in prefrontal cortex of aged female rhesus monkeys. The Journal of Neuroscience: The Official Journal of the Society for Neuroscience, 26(9), 2571-2578. https://doi.org/10.1523/JNEUROSCI.3440-05.2006

Harris, K. M., Jensen, F. E., \& Tsao, B. (1992). Three-dimensional structure of dendritic spines and synapses in rat hippocampus (CA1) at postnatal day 15 and adult ages: Implications for the maturation of synaptic physiology and long-term potentiation. The Journal of Neuroscience: The Official Journal of the Society for Neuroscience, 12(7), 2685-2705.

Henstridge, C. M., Hyman, B. T., \& Spires-Jones, T. L. (2019). Beyond the neuron-cellular interactions early in Alzheimer disease pathogenesis. Nature Reviews. Neuroscience, 20(2), 94-108. https://doi.org/10.1038/s41583-018-0113-1

Hong, S., Beja-Glasser, V. F., Nfonoyim, B. M., Frouin, A., Li, S., Ramakrishnan, S., Merry, K. M., Shi, Q., Rosenthal, A., Barres, B. A., Lemere, C. A., Selkoe, D. J., \& Stevens, B. (2016). Complement 
and microglia mediate early synapse loss in Alzheimer mouse models. Science (New York, N.Y.), 352(6286), 712-716. https://doi.org/10.1126/science.aad8373

Hong, W., Wang, Z., Liu, W., O'malley, T. T., Jin, M., Willem, M., Haass, C., Frosch, M. P., \& Walsh, D. M. (2018). Diffusible, highly bioactive oligomers represent a critical minority of soluble $A \beta$ in Alzheimer's disease brain HHS Public Access. Acta Neuropathol, 136(1), 19-40. https://doi.org/10.1007/s00401-018-1846-7

Hsieh, H., Boehm, J., Sato, C., Iwatsubo, T., Tomita, T., Sisodia, S., \& Malinow, R. (2006). AMPAR Removal Underlies A $\beta$-Induced Synaptic Depression and Dendritic Spine Loss. Neuron, 52(5), 831-843. https://doi.org/10.1016/j.neuron.2006.10.035

Kääb, S., Miguel-Velado, E., López-López, J. R., \& Pérez-García, M. T. (2005). Down regulation of Kv3.4 channels by chronic hypoxia increases acute oxygen sensitivity in rabbit carotid body: Ion channel remodelling by chronic hypoxia. The Journal of Physiology, 566(2), 395-408. https://doi.org/10.1113/jphysiol.2005.085837

Kaczmarek, L. K., \& Zhang, Y. (2017). Kv3 Channels: Enablers of Rapid Firing, Neurotransmitter Release, and Neuronal Endurance. Physiological Reviews, 97(4), 1431-1468. https://doi.org/10.1152/physrev.00002.2017

Koffie, R. M., Hashimoto, T., Tai, H.-C., Kay, K. R., Serrano-Pozo, A., Joyner, D., Hou, S., Kopeikina, K. J., Frosch, M. P., Lee, V. M., Holtzman, D. M., Hyman, B. T., \& Spires-Jones, T. L. (2012). Apolipoprotein E4 effects in Alzheimer's disease are mediated by synaptotoxic oligomeric amyloid- $\beta$. Brain, 135(7), 2155-2168. Scopus. https://doi.org/10.1093/brain/aws127

Koffie, R. M., Meyer-Luehmann, M., Hashimoto, T., Adams, K. W., Mielke, M. L., Garcia-Alloza, M., Micheva, K. D., Smith, S. J., Kim, M. L., Lee, V. M., Hyman, B. T., \& Spires-Jones, T. L. (2009). Oligomeric amyloid $\beta$ associates with postsynaptic densities and correlates with excitatory synapse loss near senile plaques. Proceedings of the National Academy of Sciences, 106(10), 4012-4017. https://doi.org/10.1073/pnas.0811698106

Kuchibhotla, K. V., Goldman, S. T., Lattarulo, C. R., Wu, H.-Y., Hyman, B. T., \& Bacskai, B. J. (2008). Abeta plaques lead to aberrant regulation of calcium homeostasis in vivo resulting in structural and functional disruption of neuronal networks. Neuron, 59(2), 214-225. https://doi.org/10.1016/j.neuron.2008.06.008

Li, S., Hong, S., Shepardson, N. E., Walsh, D. M., Shankar, G. M., \& Selkoe, D. (2009). Soluble oligomers of amyloid $\beta$-protein facilitate hippocampal long-term depression by disrupting neuronal glutamate uptake. Neuron, 62(6), 788-801. https://doi.org/10.1016/j.neuron.2009.05.012

Litvinchuk, A., Wan, Y.-W., Swartzlander, D. B., Chen, F., Cole, A., Propson, N. E., Wang, Q., Zhang, B., Liu, Z., \& Zheng, H. (2018). Complement C3aR Inactivation Attenuates Tau Pathology and Reverses an Immune Network Deregulated in Tauopathy Models and Alzheimer's Disease. Neuron, 100(6), 1337-1353.e5. https://doi.org/10.1016/j.neuron.2018.10.031

Matsuzaki, M., Ellis-Davies, G. C., Nemoto, T., Miyashita, Y., lino, M., \& Kasai, H. (2001). Dendritic spine geometry is critical for AMPA receptor expression in hippocampal CA1 pyramidal neurons. Nature Neuroscience, 4(11), 1086-1092. https://doi.org/10.1038/nn736

Matsuzaki, M., Honkura, N., Ellis-Davies, G. C. R., \& Kasai, H. (2004). Structural basis of long-term potentiation in single dendritic spines. Nature, 429(6993), 761-766. https://doi.org/10.1038/nature02617

Matus, A. (2000). Actin-based plasticity in dendritic spines. Science (New York, N.Y.), 290(5492), 754758. https://doi.org/10.1126/science.290.5492.754

Moolman, D. L., Vitolo, O. V., Vonsattel, J.-P. G., \& Shelanski, M. L. (2004). Dendrite and dendritic spine alterations in Alzheimer models. Journal of Neurocytology, 33(3), 377-387. https://doi.org/10.1023/B:NEUR.0000044197.83514.64

Noguchi, J., Matsuzaki, M., Ellis-Davies, G. C. R., \& Kasai, H. (2005). Spine-neck geometry determines NMDA receptor-dependent Ca2+ signaling in dendrites. Neuron, 46(4), 609-622. https://doi.org/10.1016/j.neuron.2005.03.015 
Ortiz-Sanz, C., Gaminde-Blasco, A., Valero, J., Bakota, L., Brandt, R., Zugaza, J. L., Matute, C., \& Alberdi, E. (2020). Early Effects of A $\beta$ Oligomers on Dendritic Spine Dynamics and Arborization in Hippocampal Neurons. Frontiers in Synaptic Neuroscience, 12, 2. https://doi.org/10.3389/fnsyn.2020.00002

Pannaccione, A., Boscia, F., Scorziello, A., Adornetto, A., Castaldo, P., Sirabella, R., Taglialatela, M., Di Renzo, G. F., \& Annunziato, L. (2007). Up-regulation and increased activity of KV3.4 channels and their accessory subunit MinK-related peptide 2 induced by amyloid peptide are involved in apoptotic neuronal death. Molecular Pharmacology, 72(3), 665-673. https://doi.org/10.1124/mol.107.034868

Penazzi, L., Tackenberg, C., Ghori, A., Golovyashkina, N., Niewidok, B., Selle, K., Ballatore, C., Smith, A. B., Bakota, L., \& Brandt, R. (2016). A $\beta$-mediated spine changes in the hippocampus are microtubule-dependent and can be reversed by a subnanomolar concentration of the microtubule-stabilizing agent epothilone D. Neuropharmacology, 105, 84-95. https://doi.org/10.1016/j.neuropharm.2016.01.002

Rowan, M. J. M., \& Christie, J. M. (2017). Rapid State-Dependent Alteration in Kv3 Channel Availability Drives Flexible Synaptic Signaling Dependent on Somatic Subthreshold Depolarization. Cell Reports, 18(8), 2018-2029. https://doi.org/10.1016/j.celrep.2017.01.068

Rowan, M. J. M., DelCanto, G., Yu, J. J., Kamasawa, N., \& Christie, J. M. (2016). Synapse-level determination of action potential duration by $\mathrm{K}+$ channel clustering in axons. Neuron, 91(2), 370-383. https://doi.org/10.1016/j.neuron.2016.05.035

Rozkalne, A., Hyman, B. T., \& Spires-Jones, T. L. (2011). Calcineurin inhibition with FK506 ameliorates dendritic spine density deficits in plaque-bearing Alzheimer model mice. Neurobiology of Disease, 41(3), 650-654. https://doi.org/10.1016/j.nbd.2010.11.014

Schneider, C. A., Rasband, W. S., \& Eliceiri, K. W. (2012). NIH Image to ImageJ: 25 years of image analysis. Nature Methods, 9(7), 671-675. https://doi.org/10.1038/nmeth.2089

Serrano-Pozo, A., Frosch, M. P., Masliah, E., \& Hyman, B. T. (2011). Neuropathological alterations in Alzheimer disease. Cold Spring Harbor Perspectives in Medicine, 1(1), a006189. https://doi.org/10.1101/cshperspect.a006189

Shi, Y., Kirwan, P., \& Livesey, F. J. (2012). Directed differentiation of human pluripotent stem cells to cerebral cortex neurons and neural networks. Nature Protocols, 7(10), 1836-1846. https://doi.org/10.1038/nprot.2012.116

Snyder, E. M., Nong, Y., Almeida, C. G., Paul, S., Moran, T., Choi, E. Y., Nairn, A. C., Salter, M. W., Lombroso, P. J., Gouras, G. K., \& Greengard, P. (2005). Regulation of NMDA receptor trafficking by amyloid- $\beta$. Nature Neuroscience, $8(8), 1051-1058$. https://doi.org/10.1038/nn1503

Song, M. S., Ryu, P. D., \& Lee, S. Y. (2017). Kv3.4 is modulated by HIF-1 $\alpha$ to protect SH-SY5Y cells against oxidative stress-induced neural cell death. Scientific Reports, 7(1), 2075. https://doi.org/10.1038/s41598-017-02129-w

Spires, T. L. (2005). Dendritic Spine Abnormalities in Amyloid Precursor Protein Transgenic Mice Demonstrated by Gene Transfer and Intravital Multiphoton Microscopy. Journal of Neuroscience, 25(31), 7278-7287. https://doi.org/10.1523/JNEUROSCI.1879-05.2005

Spires-Jones, T. L., de Calignon, A., Matsui, T., Zehr, C., Pitstick, R., Wu, H.-Y., Osetek, J. D., Jones, P. B., Bacskai, B. J., Feany, M. B., Carlson, G. A., Ashe, K. H., Lewis, J., \& Hyman, B. T. (2008). In Vivo Imaging Reveals Dissociation between Caspase Activation and Acute Neuronal Death in Tangle-Bearing Neurons. Journal of Neuroscience, 28(4), 862-867. https://doi.org/10.1523/JNEUROSCI.3072-08.2008

Spires-Jones, T. L., \& Hyman, B. T. (2014). The intersection of amyloid beta and tau at synapses in Alzheimer's disease. Neuron, 82(4), 756-771. https://doi.org/10.1016/j.neuron.2014.05.004

Spires-Jones, T. L., Meyer-Luehmann, M., Osetek, J. D., Jones, P. B., Stern, E. A., Bacskai, B. J., \& Hyman, B. T. (2007). Impaired spine stability underlies plaque-related spine loss in an 
Alzheimer's disease mouse model. The American Journal of Pathology, 171(4), 1304-1311. https://doi.org/10.2353/ajpath.2007.070055

Tackenberg, C., \& Brandt, R. (2009). Divergent pathways mediate spine alterations and cell death induced by amyloid-beta, wild-type tau, and R406W tau. The Journal of Neuroscience: The Official Journal of the Society for Neuroscience, 29(46), 14439-14450.

https://doi.org/10.1523/JNEUROSCI.3590-09.2009

Terry, R. D., Masliah, E., Salmon, D. P., Butters, N., DeTeresa, R., Hill, R., Hansen, L. A., \& Katzman, R. (1991). Physical basis of cognitive alterations in Alzheimer's disease: Synapse loss is the major correlate of cognitive impairment. Annals of Neurology, 30(4), 572-580. https://doi.org/10.1002/ana.410300410

Toombs, J., Panther, L., Ornelas, L., Liu, C., Gomez, E., Martín-lbáñez, R., Cox, S. R., Ritchie, S. J., Harris, S. E., Taylor, A., Redmond, P., Russ, T. C., Murphy, L., Cooper, J. D., Burr, K., Selvaraj, B. T., Browne, C., Svendsen, C. N., Cowley, S. A., ... Sareen, D. (2020). Generation of twenty four induced pluripotent stem cell lines from twenty four members of the Lothian Birth Cohort 1936. Stem Cell Research, 46, 101851. https://doi.org/10.1016/j.scr.2020.101851

Venegas, C., \& Heneka, Michael. (2019). Inflammasome-mediated innate immunity in Alzheimer's disease. FASEB J. https://faseb.onlinelibrary.wiley.com/doi/epdf/10.1096/fj.201900439

Wu, H.-Y., Hudry, E., Hashimoto, T., Kuchibhotla, K., Rozkalne, A., Fan, Z., Spires-Jones, T., Xie, H., Arbel-Ornath, M., Grosskreutz, C. L., Bacskai, B. J., \& Hyman, B. T. (2010). Amyloid Induces the Morphological Neurodegenerative Triad of Spine Loss, Dendritic Simplification, and Neuritic Dystrophies through Calcineurin Activation. Journal of Neuroscience, 30(7), 26362649. https://doi.org/10.1523/JNEUROSCI.4456-09.2010

Zhang, Y., \& Kaczmarek, L. K. (2016). Kv3.3 potassium channels and spinocerebellar ataxia. The Journal of Physiology, 594(16), 4677-4684. https://doi.org/10.1113/JP271343 